\title{
Targeting von Willebrand Factor in Ischaemic Stroke: Focus on Clinical Evidence
}

\author{
Nina Buchtele ${ }^{1} \quad$ Michael Schwameis $^{2} \quad$ James C. Gilbert ${ }^{3}$ Christian Schörgenhofer ${ }^{1}$ Bernd jilma ${ }^{1}$
}

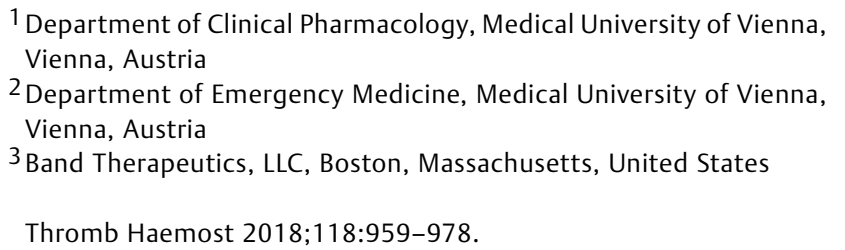

\author{
Address for correspondence Bernd Jilma, MD, Department of Clinical \\ Pharmacology, Medical University of Vienna, Waehringer Guertel \\ 18-20, A-1090 Vienna, Austria (e-mail: bernd.jilma@meduniwien.ac.at).
}

\begin{abstract}
Keywords

- stroke prevention

- von Willebrand factor

- high shear rates

- individualized treatment

Despite great efforts in stroke research, disability and recurrence rates in ischaemic stroke remain unacceptably high. To address this issue, one potential target for novel therapeutics is the glycoprotein von Willebrand factor (VWF), which increases in thrombogenicity especially under high shear rates as it bridges between vascular sub-endothelial collagen and platelets. The rationale for vWF as a potential target in stroke comes from four bodies of evidence. (1) Animal models which recapitulate the pathogenesis of stroke and validate the concept of targeting VWF for stroke prevention and the use of the VWF cleavage enzyme ADAMTS13 in acute stroke treatment. (2) Extensive epidemiologic data establishing the prognostic role of vWF in the clinical setting showing that high vWF levels are associated with an increased risk of first stroke, stroke recurrence or stroke-associated mortality. As such, vWF levels may be a suitable marker for further risk stratification to potentially fine-tune current risk prediction models which are mainly based on clinical and imaging data. (3) Genetic studies showing an association between vWF levels and stroke risk on genomic levels. Finally, (4) studies of patients with primary disorders of excess or deficiency of function in the VWF axis (e.g. thrombotic thrombocytopenic purpura and von Willebrand disease, respectively) which demonstrate the crucial role of vWF in atherothrombosis. Therapeutic inhibition of VWF by novel agents appears particularly promising for secondary prevention of stroke recurrence in specific sub-groups of patients such as those suffering from large artery atherosclerosis, as designated according to the TOAST classification.
\end{abstract}

\section{Dimensions of Stroke Burden}

Stroke remains among the top three diseases causing death and disability worldwide. ${ }^{1}$ In the United States, approximately 795,000 strokes occur each year, with an estimated incidence of 247/100,000 patient years. ${ }^{2}$ While in China, incidence rates are highest, with up to 584 events per $100,000,{ }^{3}$ incidence rates in Europe are lower, with men at higher risk $(141 / 100,000)$ than women $(95 / 100,000) .{ }^{4}$ As four out of five stroke events are of ischaemic origin, this entity constitutes the main driver for the high burden of stroke. $^{2}$

While mortality rates are decreasing in both high- and low-income countries, morbidity rates in stroke survivors are still increasing over time. ${ }^{5}$ This may suggest that while current treatment options are able to prevent death from stroke, they have only a limited impact on the preservation and/or recovery of full brain function after an ischaemic event and hence there continues to be a high rate of disability. Furthermore, due to the aging of the general received

November 29, 2017

accepted after revision

March 21, 2018
DOI https://doi.org/

10.1055/s-0038-1648251.

ISSN 0340-6245.
Copyright $\odot 2018$ Schattauer

License terms 
population, the individual's life-time risk to experience a stroke increases because age is still the main non-modifiable risk factor for cerebral ischaemia.

Besides enormous personal burden, costs in the United States for post-stroke care are estimated to be about $\$ 100$ billion each year, including direct and indirect costs. ${ }^{6}$ Within Europe, costs are estimated to be about $\$ 27$ billion annually, accounting $\$ 18.5$ billion for direct costs and $\$ 8.5$ billion for indirect costs. ${ }^{7}$

Many promising options for prevention and treatment of ischaemic stroke have been tested, including invasive endovascular techniques and conservative medical management strategies, but only a limited number of treatments have gained approval by the Food and Drug Administration and the European Medicines Agency for either stroke prevention and/or treatment within the last decade.

Development of pharmacotherapy for ischaemic stroke indications continues to lag behind than that for myocardial infarction. Especially in regard to anti-platelet therapy, many drugs with a favourable benefit:risk ratio in coronary disease have not proven beneficial in cerebrovascular disease, where the intrinsic susceptibility to treatment-induced bleeding is seemingly increased. These include: heparin, the GPIIb/IIIa inhibitors abciximab and tirofiban, ${ }^{8,9}$ newer P2Y12-receptor blockers such as prasugrel ${ }^{10}$ and the thrombin-receptor antagonist vorapaxar. ${ }^{11}$ There is a particular unmet need in anti-thrombotic pharmacotherapy for secondary stroke prevention, which currently only includes aspirin or aspirindipyridamole and possibly in some circumstances clopidogrel.

Improved understanding of ischaemic stroke pathogenesis at the molecular level and the identification of high-risk sub-types of stroke should enable development of novel and specific treatment strategies. In recent years, von Willebrand factor (vWF) has been consistently implicated in the epidemiologic literature as a risk factor for ischaemic stroke. Its role in platelet thrombogenesis at sites of arterial vascular injury in the presence of high shear force, and functional 'silence' in other vascular beds in the absence of shear force, makes it a logical target for primary and secondary stroke prevention, and possibly also for stroke treatment.

This review summarizes available evidence for the rationale for vWF inhibition in ischaemic stroke in the light of disadvantages of currently used pharmacotherapy, suggests how these may be addressed by targeting the GPIb-vWF axis and discusses stroke populations that may benefit from vWFtargeted therapy. Animal studies that improved understanding of the impact of vWF on stroke have recently been thoroughly reviewed by Denorme and De Meyer ${ }^{12}$ and thus will not be discussed in detail.

\section{Pathomechanism of von Willebrand Factor in Stroke}

Ischaemic brain injury arises in conditions of insufficient blood supply. This results from thrombosis, emboli or systemic hypo-perfusion, which together account for approximately $80 \%$ of all strokes. Specifically, large artery atherosclerosis (LAA, per the Trial of ORG 10172 in Acute
Stroke Treatment [TOAST] classification ${ }^{13}$ ) accounts for $16 \%$ of all ischaemic strokes in the United States, ${ }^{14}$ and for $25 \%$ in China. ${ }^{3}$ Atherosclerotic lesions cause obstruction, which further promotes thrombus formation and embolizationresulting in reduced cerebral blood flow.

An important player in the propagation of thrombus formation and atherosclerosis is the blood glycoprotein vWF, which functions as a molecular bridge linking platelets and sub-endothelial collagen after vascular injury and furthermore serves as a chaperone for factor VIII (FVIII). VWF protects FVIII from proteolytic inactivation by activated protein $\mathrm{C}$ and $\mathrm{S} .{ }^{15}$ Therefore, low vWF levels are accompanied by low FVIII levels, which in combination exaggerate a bleeding tendency.

Endothelium-derived vWF is synthesized mainly within endothelial cells. After several post-translational modifications including cleavage of a propeptide, both mature vWF and the propeptide are stored in Weibel-Palade bodies. ${ }^{16}$ In response to inflammation, ${ }^{17}$ histamine, ${ }^{18}$ thrombin, ${ }^{17,19,20}$ fibrin or to exogenous desmopressin, ${ }^{21}$ Weibel-Palade bodies fuse with the endothelial membrane and release ultra-large vWF multimers and its cleaved propeptide. While the latter is intra-cellularly required for multimerization and storage of vWF, its function in the bloodstream is not entirely clear. $^{22}$ Upon release, ultra-large vWF strands are cleaved by ADAMTS13 into smaller multimers, which circulate inactively in a coiled conformation in plasma. Exposure to subendothelial collagen after vascular damage uncoils and thereby activates vWF multimers, exposing their GP1b-binding sites and facilitating platelet adhesion. The higher the shear rate, the more successfully the unfolding process proceeds resulting in a size-dependent globule-stretch transition. ${ }^{23}$ This underlines the role of vWF in atherothrombosis, where obstructions cause high blood velocity and shear.

Thrombus initiation by vWF-GPIb interactions is a crucial step, because it promotes platelet-rolling on the injured vessel wall and further engagement of platelet receptors and their substrates. One of these platelet receptors is GPIIbIIIa, which is not only capable of binding to fibrinogen, but also to vWF itself. However, while vWF-GPIb interactions are substantial for thrombus initiation, vWF-collagen and vWF-GPIIbIIIa mainly contribute to thrombus growth. ${ }^{24}$

vWF has also been linked to numerous pathological processes including angiogenesis, cell proliferation and inflammation. Several mechanisms are involved in vWFmediated inflammation, specifically platelet interactions and the GPIb-vWF axis. Direct interactions at low shear rates between vWF and leukocytes, as well as vWF-induced increased vascular permeability, diapedesis of leukocytes and accumulation of vWF in the extra-vascular space all promote inflammation. ${ }^{25}$ Further potentiation of inflammation can result from low ADAMTS13 activity, as ultra-large vWF strings work in concert with P-selectin to promote platelet aggregation and platelet-induced leukocyte recruitment.

Inflammation plays a major role in atherothrombosis, highlighting its importance in ischaemic stroke. Arteriosclerosis is a localized inflammatory process in which 
increased amounts of ultra-large vWF strings are released from Weibel-Palade bodies under shear stress and attached to the inflamed endothelial surface. Cholesterol-induced atherosclerotic plaques were shown to contain high levels of Weibel-Palade bodies and vWF deposits. ${ }^{26,27}$ Activated platelets trapped by endothelial vWF amplify the inflammatory process by recruiting leucocytes, macrophages and further platelets which in turn trigger the development of large vWF strings. ${ }^{28}$ Progressing plaque formation increases shear stress, which again promotes further exocytosis of endothelial Weibel-Palade bodies. Due to reduced synthesis and increased thrombin cleavage, ADAMTS13 activity is impaired under inflammatory conditions facilitating the subsequent development of hyperactive vWF multimers. ${ }^{29}$ In addition, vWF was shown to directly stimulate the proliferation of smooth muscle cells, a crucial component of arteriosclerotic lesions. ${ }^{30}$ However, while vWF deficiency protects mice from atherosclerosis, ${ }^{30}$ this protective effect has not been demonstrated in patients with von Willebrand disease. ${ }^{31}$ Results from murine models must always be considered in the light that mice are not men. As wildtype mice are relatively resistant to atherosclerosis, ApoE knockout mice are most frequently used. With this genetic modification, vessel stenosis are more likely related to a process of angiogenesis and not to unstable atherosclerotic plaque formation, ${ }^{32}$ which at least partly limits the translation of results from murine models into humans.

It is conceivable that pharmacological vWF inhibition may limit or even prevent development of atherothrombosis at vascular sites of high shear stress, but further studies are needed to conclusively define the potential of vWF as therapeutic target in the prevention or treatment of arteriosclerosis per se.

\section{The Role of von Willebrand Factor in Stroke -Insights from Epidemiological Studies}

As vWF is critically involved in platelet aggregation and thrombus formation upon endothelial activation, it has been studied intensively as a potential risk factor for stroke and stroke-related outcome.

An association between vWF levels, the risk of first-ever ischaemic stroke, ${ }^{33,34}$ stroke recurrence, ${ }^{35}$ stroke severity, ${ }^{36,37}$ post-stroke morbidity ${ }^{38,39}$ and mortality ${ }^{40}$ has been reported by several studies (-Table 1; - Supplementary Table $\mathbf{S 1}$ and S2, available in the online version). Many of them were observational and case-control studies, which investigated vWF levels by use of various assays at the time of the acute ischaemic event.

Several laboratory tests are available for assessing vWF activity and vWF quantity (-Table 2). Measurements for $\mathrm{vWF}$ activity comprise the ristocetin cofactor assay (vWF: $\mathrm{RCo}$ ) and collagen-binding assay (vWF:CB). The observation that ristocetin induces platelet aggregation led to the development of the first quantitative assay to determine vWF activity. Ristocetin alters vWF confirmation which provides the exposure of GPIb binding sites to facilitate platelet aggregation. Therefore, the vWF:RCo assay reflects the inter- action between vWF and its cognate platelet receptor GPIb. Collagen-binding provides another essential part of platelet plug formation and therefore collagen-binding assays reflect vWF activity as well. vWF:CB may be useful as companion to vWF:RCo assays to reduce error rates due to test variability and sensitivity. ${ }^{41}$ However, with respect to vWF in stroke, to date only vWF:RCo tests have been used to determine vWF activity.

vWF can be measured quantitatively by either vWF:Ag or vWF:pp. As mature vWF and vWF propeptide differ in their kinetics, the assessment of both helps in determining vWF secretion, clearance and survival. The half-life of vWF propeptide is 2 to 3 hours and therefore shorter than the 8 to 10 hours half-life of mature vWF. ${ }^{42}$ Furthermore, vWF propeptide is independent of blood type and ADAMTS13 activity, making it a more sensitive marker for vWF release. To date, only few studies investigated both vWF:Ag and vWF:pp levels, probably reflecting the wider availability of vWF:Ag assays. However, when interpreting results from stroke studies investigating vWF levels, disadvantages of the used methods need to be taken into account for the distinct method (-Table 2 ).

\section{Elevated vWF Levels in Stroke: Cause or Consequence?} Supportive evidence for a causative role of vWF in stroke comes from animal models, which have consistently shown that deficiency in VWF is protective against cerebral ischaemia. ${ }^{43,44}$ Likewise, patients with von Willebrand disease are known to have a reduced risk of arterial thrombosis. ${ }^{45}$ Conversely, observations in acquired thrombotic thrombocytopenic purpura patients underline the crucial role of vWF in stroke, as hereby the accumulation of ultra-large vWF multimers due to an autoantibody-induced decreased activity of ADAMTS13 leads to thrombotic complications such as stroke or myocardial infarction. ${ }^{46}$

Numerous case-control studies that determined vWF levels at the time of ischaemic stroke showed a significant increase in vWF as compared with controls. ${ }^{33,37,47-52}$ However, due to the nature of their study design, no assumptions on the cause-effect relationship can be made, i.e., whether elevated vWF levels reflect a risk of developing first-ever stroke or simply mirror inflammation and an activation of the haemostatic system and are therefore a consequence of acute ischaemia. For example, vWF levels correlate with Creactive protein (CRP) levels on admission; ${ }^{37}$ however, data are conflicting concerning persisting elevation of VWF in the late phase after stroke. ${ }^{33,49,51,52}$

Markers closely associated with vWF, such as ADAMTS13 and FVIII, are also significantly different between stroke patients and controls; e.g., higher FVIII levels ${ }^{47}$ and lower ADAMTS13 activity are found in stroke patients. ${ }^{51}$ While there are no data on FVIII levels in the late phase after stroke, ADAMTS13 activity increases to normal levels. ${ }^{51}$

Still, low ADAMTS13 activity might be an independent risk factor for stroke occurrence as shown by a large observational case-control study in young women with stroke in which the ADAMTS13 measurements were performed in the very late phase after stroke. The retrospective odds ratio (OR) for first-ever stroke comparing the lowest quartile to the 


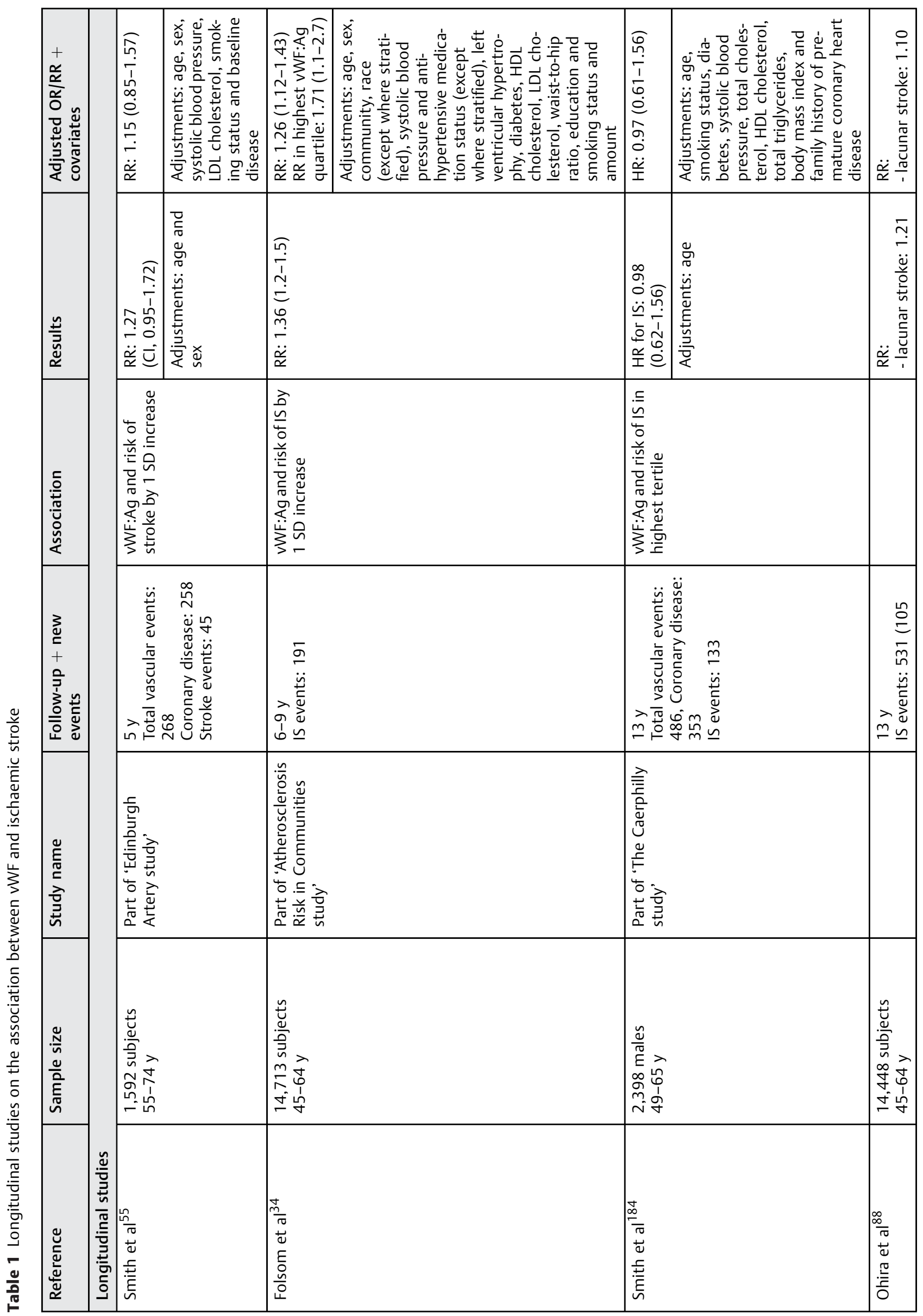




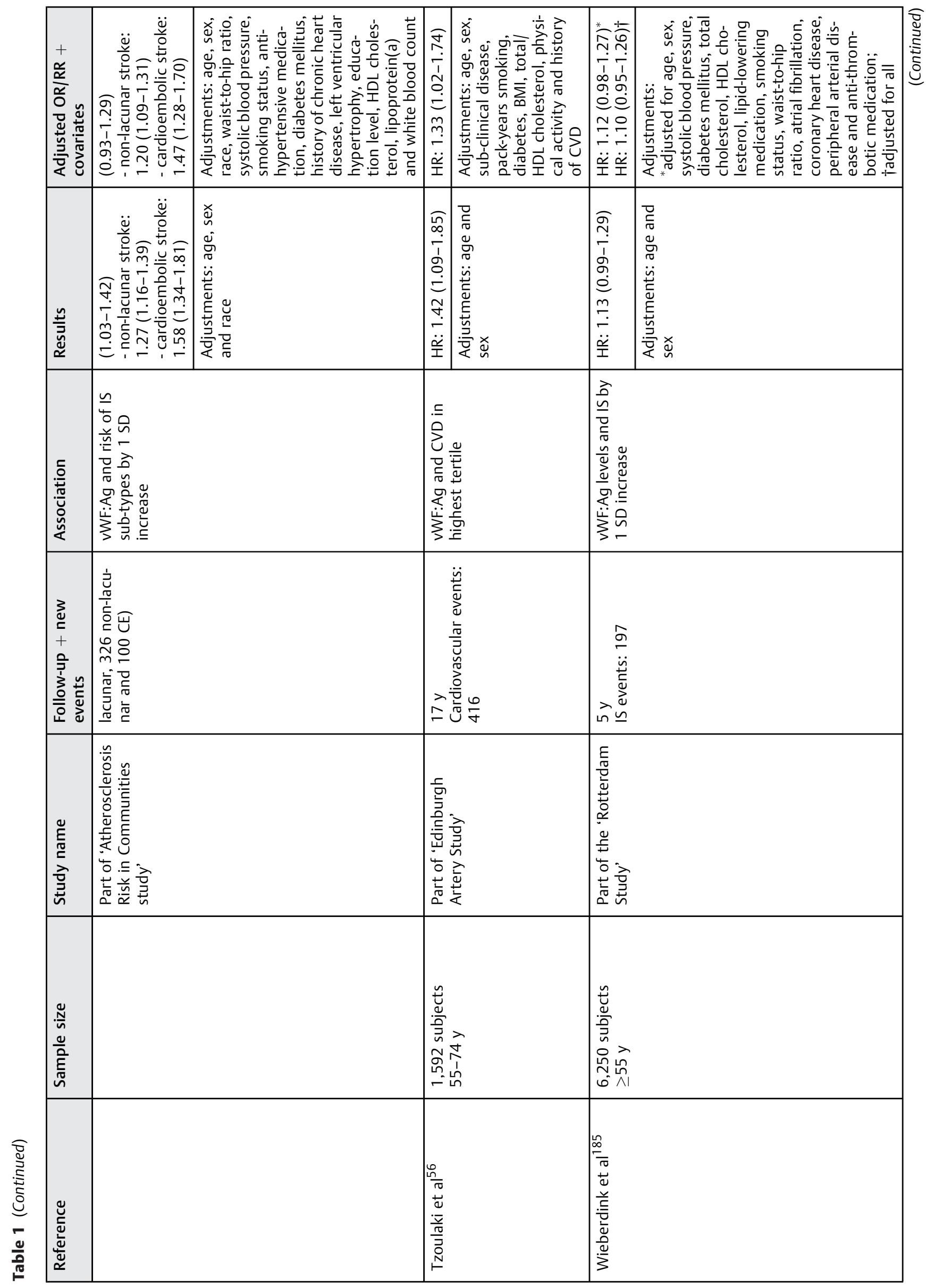



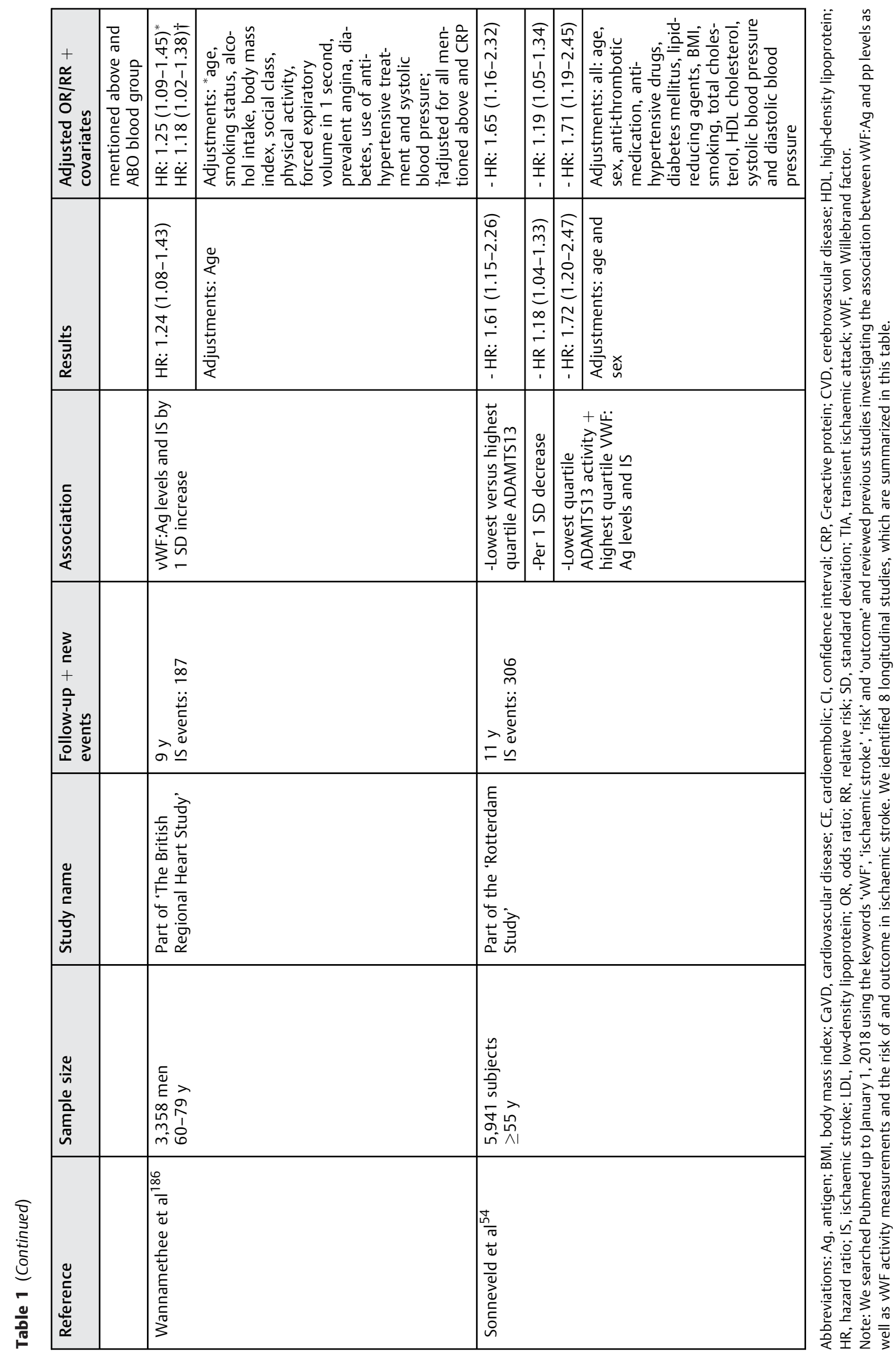
Table 2 Laboratory methods to determine von Willebrand factor levels

\begin{tabular}{|c|c|c|c|c|c|}
\hline & Measurement & Principle & Method & Advantage & Disadvantage \\
\hline $\begin{array}{l}\text { vWF antigen (vWF: } \\
\mathrm{Ag})^{\mathrm{a}}\end{array}$ & Quantity & $\begin{array}{l}\text { Antibody captures } \\
\text { protein }\end{array}$ & $\begin{array}{l}\text { ELISA, LIA or flow } \\
\text { cytometry }\end{array}$ & $\begin{array}{l}\text { High availability in } \\
\text { laboratories }\end{array}$ & $\begin{array}{l}\text { Different cut-off } \\
\text { values for differ- } \\
\text { ent assays } \\
\text { Not sensitive for } \\
\text { low levels } \\
\text { No differential } \\
\text { sensitivity to vari- } \\
\text { able molecular } \\
\text { weight forms of } \\
\text { vWF }\end{array}$ \\
\hline $\begin{array}{l}\text { vWF propeptide } \\
\text { (vWF:pp) }\end{array}$ & Quantity & $\begin{array}{l}\text { Antibody captures } \\
\text { protein }\end{array}$ & ELISA & $\begin{array}{l}\text { Sensitive para- } \\
\text { meter for vWF } \\
\text { release }\end{array}$ & $\begin{array}{l}\text { Different cut-off } \\
\text { values for differ- } \\
\text { ent assays } \\
\text { Little commercial } \\
\text { availability }\end{array}$ \\
\hline $\begin{array}{l}\text { vWF ristocetin co- } \\
\text { factor (vWF:RCo) }\end{array}$ & Activity & $\begin{array}{l}\text { Ristocetin induces } \\
\text { platelet aggrega- } \\
\text { tion through } \\
\text { GPIb-vWF } \\
\text { interaction }\end{array}$ & $\begin{array}{l}\text { Aggregometry, } \\
\text { standard coagula- } \\
\text { tion instruments, } \\
\text { LIA or flow } \\
\text { cytometry }\end{array}$ & $\begin{array}{l}\text { High availability in } \\
\text { laboratories } \\
\text { Availability at the } \\
\text { bedside with } \\
\text { timely results }\end{array}$ & $\begin{array}{l}\text { High variation of } \\
\text { coefficients } \\
\text { Limited inter- } \\
\text { laboratory repro- } \\
\text { ducibility and } \\
\text { standardization } \\
\text { Poor sensitivity for } \\
\text { low vWF levels }\end{array}$ \\
\hline $\begin{array}{l}\text { vWF collagen } \\
\text { binding (vWF:CB) }\end{array}$ & Activity & $\begin{array}{l}\text { Collagen induces } \\
\text { vWF binding }\end{array}$ & $\begin{array}{l}\text { ELISA or flow } \\
\text { cytometry }\end{array}$ & $\begin{array}{l}\text { Sensitivity to high } \\
\text { molecular weight } \\
\text { vWF } \\
\text { Sensitivity to low } \\
\text { vWF levels } \\
\text { Little variability }\end{array}$ & $\begin{array}{l}\text { Lack of compara- } \\
\text { tive data }\end{array}$ \\
\hline vWF activity & Activity & $\begin{array}{l}\text { Recombinant gain } \\
\text { of function GPIb } \\
\text { binds to vWF }\end{array}$ & LIA or ELISA & $\begin{array}{l}\text { Easy performance } \\
\text { and automation } \\
\text { High assay accu- } \\
\text { racy and precision } \\
\text { Detection of vWF } \\
\text { at low levels }\end{array}$ & $\begin{array}{l}\text { Lack of compara- } \\
\text { tive data }\end{array}$ \\
\hline
\end{tabular}

Abbreviations: ELISA, enzyme-linked immunosorbant assay; GPIb, glycoprotein Ib; LIA, latex-particle immunoassay; vWF, von Willebrand factor. Note: Key points for different assessment of von Willebrand factor.

andicates tests used in stroke studies.

highest quartile of convalescent ADAMTS13 activity was 3.1 (1.6-5.8), even after adjustment for several risk factors. ${ }^{52}$ The combination of high vWF levels and low ADAMTS13 activity are the most crucial haemostatic factors for developing stroke. ${ }^{53,54}$

Evidence for the causative role of vWF in stroke comes from large longitudinal studies that investigated strokenaïve patients and analysed their stroke prevalence with respect to baseline vWF levels and ADMTS13 activity (-Table 1). Smith et al demonstrated a trend to an increased stroke-risk according to vWF levels in 'the Edinburgh study'. They prospectively determined vWF levels in almost 1,600 stroke-naïve participants at baseline with a follow-up for cardiovascular events after 5 years. The age- and sexadjusted relative risk was nominal 1.27 (confidence interval [CI], 0.95-1.72; for every unit increase in vWF-antigen level on a logarithmic scale), but this was not statistically significant. ${ }^{55}$ In the same study cohort after a prolonged followup period of 17 years, the number of strokes in the popula- tion quadrupled and then the association of stroke risk and vWF antigen level became statistically significant, with the hazard ratio (HR) adjusted for age and sex of 1.42 (CI, 1.091.85) comparing top versus bottom tertile of vWF antigen. ${ }^{56}$

In a much larger sample size, the 'Atherosclerosis Risk in Communities study' showed a positive association between baseline vWF levels and the risk of stroke occurrence. In this prospective study that followed more than 14,000 patients free of cardiovascular disease for up to 9 years, the risk of stroke in patients in the highest vWF quartile was 1.7 (CI, 1.1-2.7) times higher than in those in the lowest vWF quartile. Likewise, in an observational case-control study of patients with first time stroke, the risk of stroke increased by $80 \%$ with every quartile of vWF determined at the time of ischaemic event. ${ }^{33}$ This finding might indicate that there could be a certain threshold level at which vWF becomes detrimental.

Further supporting data come from the 'Rotterdam study', another prospective population-based cohort study that 
followed more than 6,000 patients, who were free from stroke at baseline over a median follow-up time of more than 10 years $(56,403$ total person-years).

Increasing vWF levels were associated with a significant increase in the risk of stroke (HR per standard deviation increase: 1.12 [CI, 1.01-1.25]). In a subsequent analysis of the Rotterdam study population, Sonneveld et al were the first to perform a combined analysis for vWF-antigen and ADAMTS13 activity in a longitudinal study. Patients with high vWF Antigen levels ( $\geq 75$ th percentile) along with low ADAMTS13 activity ( $\leq 25$ th percentile) were at a significantly increased risk for ischaemic stroke with a HR of 1.71 (CI, 1.19-2.45; absolute risk, 9.1\%). ${ }^{54}$

Taken together, these data support the rationale that not only vWF levels, but also the vWF-modifying enzyme ADAMTS13 plays an important role in the development of first-ever stroke. Therefore, screening patients free of stroke at preventive check-ups could help to identify high-risk patients, stratifying them for risk of future stroke based on their vWF levels and/or ADAMTS13 activity.

\section{vWF Levels, Stroke and Genetics: All a Hereditary Risk?}

Recent genome wide association studies identified several gene loci linked to sub-types of ischaemic stroke, ${ }^{57-62}$ and genetic polymorphisms have gathered increased attention as tools for stratifying stroke risk. Genetics impact the risk of first-ever stroke, stroke recurrence and recanalization rates. $^{35,63,64}$

vWF plasma levels are strongly heritable ${ }^{65}$ and determined by several genetic factors ${ }^{66-70}$ including the $A B O$ blood group, ${ }^{71-77}$ vWF gene variants and single nucleotide polymorphisms. ${ }^{76,78-81}$ The plasma concentration of vWF in individuals with blood group 0 is approximately $25 \%$ lower compared with those with types non-0. Therefore, the question arises whether the latter are at higher risk to develop ischaemic events. Data support this rationale in myocardial infarction, ${ }^{82}$ but so far data from stroke patients did not confirm this hypothesis. Despite 25\% lower vWF levels in type 0 individuals, the stroke risk was higher in patients in the highest vWF quartile with blood group 0 as compared with non- 0 . Yet, the mechanism behind this is unclear. ${ }^{33}$

Genetic determinants and vWF levels were investigated with respect to overall stroke risk in the large prospective Rotterdam study. However, no genetic predictor of stroke risk was found while higher genetic scores correlated with vWF levels. ${ }^{63}$ The authors therefore concluded that genetic variants may still determine cardiovascular and stroke risk in younger individuals, but that this trend was not demonstrated in the elderly Rotterdam study population. ${ }^{83}$ However, variants of the ABO locus, which is an important determinant of vWF plasma levels, ${ }^{35,63,71,72}$ were associated with large-vessel and cardioembolic but not small-vessel stroke. ${ }^{84}$ Given the importance of thrombotic factors in the former two stroke sub-types, it seems rational that vWF and its genetics play an important role in these sub-types of stroke.

\section{Assessment of vWF to Predict Outcome and Stroke Recurrence}

Data for the impact of vWF levels on stroke outcome and the risk for stroke recurrence came from observational and casecontrol studies. vWF levels were measured at the time of first ischaemic event and therefore no clear assumption can be made if vWF determines post-stroke morbidity and mortality as well as recurrence or only predicts outcome in stroke patients.

In this context, Carter et al found that 3-year mortality from stroke increases with vWF activity ranging from $16 \%$ in those with levels $<135 \%$ (normal $=100 \%$ ) to $52 \%$ in patients with vWF levels $>243 \%{ }^{40}$ Those who died within 30 days $(\sim 5 \%)$ had total arterial circulation infarction more frequently as compared with patients dying after 30 days. Further data from the same study population showed that with every unit increase in vWF levels on a logarithmic scale, the risk of 6 -month mortality increased by $73 \%{ }^{47}$ Two recent smaller observational studies confirmed the association between high vWF levels and poor outcome. ${ }^{36,38}$ Followup in these studies using disability scores was only until discharge and therefore increased vWF levels might reflect activation of inflammation and only mirror the extent of ischaemia.

With respect to stroke recurrence, few data are available. Williams et al showed that elevated vWF levels increase the risk for stroke recurrence in both unadjusted ( $p=0.0007$; HR, 1.26) and fully adjusted ( $p=0.018$; HR, 1.19) models. Tools to predict early stroke recurrence integrate only clinical and/or imaging information, but accuracy might improve taking laboratory parameters into account. ${ }^{85,86}$ Therefore, vWF might serve as a potential candidate given its important pathophysiologic role as acute phase protein and in LAA, where stroke recurrence is deemed to be highest. We still lack confirming data, but given the fact that stroke recurrence is highest shortly after stroke, it would be desirable to gain new data on early stroke recurrence with respect to vWF levels.

\section{The Role of von Willebrand Factor according to Stroke Sub-Type}

vWF levels are significantly higher in large- than in smallvessel disease. ${ }^{47,49}$ High levels of vWF in LAA (defined above) sub-type of stroke compared with other sub-types have also been reported by Sonneveld et al in a large observational study. These authors additionally found a strong association between vessel calcification volume in the aortic arch and carotid arteries and plasma vWF levels at the time of ischaemic event in 925 patients. ${ }^{87}$ Longitudinal assessments further confirmed these associations between vWF and the development of atherosclerotic-driven stroke, suggesting a causative role of vWF in specific stroke sub-types. ${ }^{88}$

Therefore, these findings suggest that the LAA sub-type of stroke could be particularly sensitive to a vWF blocking strategy. This is plausible considering the key role of vWF in shear stress-dependent haemostasis at the site of vessel stenosis and plaques. ${ }^{31}$ This may be especially relevant with respect to patients with carotid stenosis, who are known to 
have a high risk of stroke recurrence, as they have persistently elevated vWF levels after the first ischaemic event, ${ }^{52}$ which may explain their high risk of stroke recurrence despite the use of conventional anti-platelet drugs. Of note, platelet function measured under high shear stress is minimally affected by conventional anti-platelet drugs including aspirin, ${ }^{89}$ clopidogrel, $^{90}$ prasugrel $^{91}$ or tirofiban $^{92}$ in the presence of high vWF levels. Furthermore, it is unclear, whether vWF levels are altered by initiation of anti-platelet therapy with aspirin or clopidogrel per se. ${ }^{93,94}$

\section{Shortcomings of Current Stroke Prevention and Treatment}

\section{Limitations of Acute Ischaemic Stroke Treatment}

To date, the only Food and Drug Administration-approved medication for acute ischaemic stroke is recombinant tissue plasminogen activator (rtPA), based on the results from the National Institute of Neurological Disorders and Stroke (NINDS) landmark study published in $1995 .{ }^{95}$ Since then no single new medication has gained approval. Twelve trials have been published so far that compared the effects of thrombolytic agents and placebo of which only two showed positive outcomes: the NINDS part II study and the ECASS-III trial. ${ }^{95,96}$ Still, in a meta-analysis of 12 randomized trials, treatment with rtPA significantly decreased mortality and disability, especially if administered within 3 hours after symptom onset. ${ }^{97}$

More recently, mechanical endovascular interventions have been introduced into the standard of care for acute stroke management, and in 2015, the current guidelines for acute stroke treatment were updated and mechanical treatment with or without rtPA is recommended. Stent retrievers are recommended in addition to rtPA in internal carotid artery or middle cerebral artery-M1 occlusion. ${ }^{98}$

\section{The Issue of Time Delay}

Intravenous thrombolysis is only administered to $5.2 \% 99,100$ of all ischaemic stroke patients in the United States and 1.2\% of Chinese patients. ${ }^{101}$ The most critical criterion for exclusion is the time window of $<4.5$ hours from stroke onset to treatment initiation. But still the majority of the patients who do arrive within the time window still do not receive rtPA for various reasons: because their stroke is not deemed severe enough, their symptoms improve rapidly or they have comorbidities such as hypertension that are believed to increase the risk of intra-cranial haemorrhage. ${ }^{102-104}$ In developing countries, insufficient time to complete imaging studies and intra-hospital delay is another particularly critical issue. ${ }^{101}$ The actual proportion of patients eligible for thrombolysis is very difficult to establish, as many co-factors need to be taken into account when interpreting thrombolysis rates. For example, thrombolysis rates differ between specialized centres that receive referral patients pre-determined to be eligible for thrombolytic treatment and smaller less specialized hospitals treating 'all comers'. In several countries and federal states, thrombolysis proportions have reached 15 to $20 \%$ in specialized referral stroke treatment centres.
Although there is some evidence that mechanical thrombectomy is beneficial in a time window of up to 12 hours after symptom onset, i.e., when rtPA is not further indicated, definitive data are still lacking. However, a recent randomized controlled trial showed that thrombectomy was still beneficial if performed 6 to 24 hours after stroke onset in patients with a mismatch between infarct size and clinical disability. Thirty-three per cent more patients achieved functional independence by 90 days (modified Rankin Scale score $0-2$ ) in the arm receiving thrombectomy plus standard medical care compared with those in the arm receiving standard medical care alone. As the sample size was rather small with 206 enrolled patients, larger trials confirming this benefit are still warranted. ${ }^{105}$

\section{Risks Attributed to Thrombolysis}

In patients with myocardial infarction and pulmonary embolism who receive thrombolysis with rtPA, the risk for symptomatic intra-cranial bleeding is 1 to $1.5 \% .{ }^{106}$ However, in patients with stroke receiving rtPA the bleeding risk is 5 to $8 \%$ and increases up to $13 \%$ in those who re-canalize late. ${ }^{106}$ The odds of intra-cranial haemorrhage double with co-morbidities such as atrial fibrillation, congestive heart failure and renal impairment, as well as in those patients taking antiplatelet medication. ${ }^{107}$ Recombinant tPA interacts with several proteins and receptors, thereby impairing blood-brain barrier integrity and increasing the susceptibility of neurons to excitotoxicity by modulation of $\mathrm{N}$-methyl-D-aspartate (NMDA) receptors, which emerging data suggest is a major cause of neuronal death after ischaemia. ${ }^{108}$

\section{Limited Recanalization Rates}

However, in the limited number of patients who receive thrombolytics, early recanalization 2 hours after the start of rtPA treatment is achieved in approximately 50\% of patients, ${ }^{109}$ varying between occluded vessel sites but with the highest success rate in middle cerebral artery-M1 occlusion. ${ }^{106}$ This may reflect the responsiveness of different thrombus sub-types to thrombolysis. Fibrin-rich clots mainly arise from cardiac embolism and are more sensitive to thrombolysis than are vWF-rich clots, which in general result from atherothrombosis and large vessel disease, not cardiac embolism. ${ }^{110}$ About one-third of patients achieve late recanalization, which is accompanied by poor outcome caused by longer ischaemia. ${ }^{109}$

\section{Open Questions for Endovascular Treatment}

Besides clarity concerning the beneficial time window for mechanical clot retrieval, definitive evidence concerning the best endovascular treatment option is still lacking. To date, mechanical stent-retrievers are the most promising devices. ${ }^{111}$ This method combines the advances of prompt flow restoration with stenting and mechanical clot retrieval. While three earlier trials investigating endarterectomy devices showed no benefit, ${ }^{112}$ five trials performed between 2010 and $2015^{111}$ showed a decrease in disability as well as an increase in functional independence in patients treated with an intraarterial mechanical thrombectomy approach ${ }^{111}$; rates of 
intra-cranial bleeding were comparable between patients receiving the intervention and those receiving conventional therapy. Mortality rates in all five positive trials trended favourably but did not differ significantly between the intervention and the control group, 15.3 and $18.9 \%$, respectively. ${ }^{111}$ Rates of other intervention-specific complications, e.g., perforation of vessels, increase when the physician performing the treatment has limited experience in this area. This restricts the ability to offer mechanical treatment options to stroke centres with high patient volume, as these have the requisite resources and expertise. ${ }^{113}$

Furthermore, there are only limited data for combined treatment with mechanical thrombectomy and concomitant anti-platelet agents. In a prospective study, administration of tirofiban in addition to endovascular thrombectomy was safe and associated with lower odds of death. ${ }^{114}$ Given the crucial role of vWF under high shear rates, an anti-vWF approach in addition to mechanical clot retrieval potentially could be the optimal therapeutic strategy to prevent vessel re-occlusion and positively affect outcome after the procedure.

\section{Limitations of Secondary Stroke Prevention}

Besides modification of traditional risk factors for stroke, such as hypertension, diabetes mellitus, smoking, dyslipidaemia and physical inactivity, ${ }^{115}$ platelet inhibitors are the cornerstones of secondary non-cardioembolic ischaemic stroke prevention. Recent guidelines recommend antithrombotic mono-therapy with aspirin, or with aspirin and extended-release dipyridamole, or with the adenosine diphosphate-receptor blocker clopidogrel as equivalent alternatives. ${ }^{116}$ Furthermore, cilostazol, a phosphodiesterase inhibitor, showed significant benefit in Asian patients for the prevention of stroke and other serious vascular events. However, to date cilostazol has not gained approval for secondary stroke prevention and has not yet been tested in a non-Asian population. ${ }^{117}$ With regards to the individual choice of anti-platelet therapy, there is insufficient evidence to support the use of one agent over another.

Two previous trials, however, reported greater benefit for secondary stroke risk reduction with aspirin plus extendedrelease dipyridamole than with aspirin alone ${ }^{118}$; and the CAPRIE trial, which compared clopidogrel to aspirin in 19,185 patients with symptomatic vascular disease, found clopidogrel to be of minor superiority (relative risk reduction of $8.7 \%$ in favour of clopidogrel; $\mathrm{Cl}, 0.3-16.5, p=0.043$ ) over aspirin for the intention-to-treat population regarding the primary combined end point of ischaemic stroke, myocardial infarction or vascular death. ${ }^{119}$ However, in the stroke subpopulation the relative risk reduction of $7.3 \%(\mathrm{Cl},-5.7$ to 18.7) was not significant $(p=0.26)$.

While data from animal studies showed a possible neuroprotective effect of aspirin with or without dipyridamole, ${ }^{120}$ this has not been shown for clopidogrel. ${ }^{121}$ Comparing aspirin-dipyridamole to clopidogrel in stroke patients, the net risk of recurrent stroke is similar but still $9 \%$ in each group of the ProFess trial, which prospectively followed more than 20,300 patients over 2.5 years. ${ }^{122}$ The use of clopidogrel was even associated with an increased severity of recurrent stroke in a post hoc sub-group analysis of that trial. ${ }^{123,124}$ This may reflect the lack of a neuroprotective effect of clopidogrel. ${ }^{121}$

Short-term dual anti-platelet therapy with aspirin and clopidogrel for 90 days is indicated only in high-risk patients with symptomatic intra-cranial large artery disease, as these patients are known to have a high risk of early stroke recurrence after first-ever transient ischaemic attack. Aspirin and clopidogrel in combination, however, should not be used for long-term stroke prevention because of a lack of superiority compared with clopidogrel alone together with a substantially increased risk of major bleeding events. ${ }^{125,126}$

The critical issue in secondary stroke prevention is finding the right balance between sufficient anti-platelet effects and a low bleeding risk. Recent data focusing on major bleeding events showed that the cumulative 3-year major bleeding risk for stroke patients on anti-platelet therapy was overall $23 \%$. Risk for ischaemic events despite anti-platelet therapy was even above $60 \%{ }^{127}$ This is an unacceptably high event rate and therefore carefully selected patients might benefit from an individualized, more effective anti-platelet therapy with an agent that is less likely to promote bleeding complications.

\section{High On-Treatment Platelet Reactivity}

One reason for the limited potency of aspirin and clopidogrel in secondary stroke prevention may be mediated by haemostatic mechanisms of platelet activation and thrombus formation that are independent from platelets' cyclooxygenase and adenosine diphosphate receptor pathways. Twenty years ago, it was already demonstrated that shear-induced platelet aggregation mediated by exogenous or platelet-derived vWF cannot be inhibited by aspirin in vitro. ${ }^{128}$

In a recent longitudinal observational study investigating platelet function by means of multiple electrode aggregometry in 624 stroke patients on anti-platelet therapy, $11 \%$ of patients with a stroke while on aspirin had high on-treatment platelet reactivity, and treatment with clopidogrel was accompanied by even higher proportions of unresponsiveness (36\%), independent of the etiologic sub-type of stroke. ${ }^{129}$ Rates of responsiveness to clopidogrel were not associated with CYP2C19 polymorphisms. In this context, Kunicki et al investigated the effect of aspirin on platelet function in 463 patients with stroke, transient ischaemic attack or acute coronary syndrome. ${ }^{130}$ Aspirin non-responsiveness measured by Platelet Function Analyzer-100 significantly increased with vWF levels $(p<0.001)$, which likely contributes to the resistance to the inhibitory effects of aspirin under high shear rates. ${ }^{128}$

Clopidogrel's efficacy in preventing stroke likely depends on CYP2C19 genetic variants, which determine conversion of the inactive pro-drug to its active metabolite. Clopidogrel in addition to aspirin reduced the risk of recurrent stroke only in patients who did not carry CYP2C19 loss-of-function alleles in a large trial involving almost 3,000 patients with minor ischaemic stroke or transient ischaemic attack. ${ }^{131}$ The increased risk of stroke in carriers of this allele (risk ratio, 1.92 , CI, 1.57-2.35; $p<0.001$ ) was confirmed by a recent 
meta-analysis, which analysed 15 studies with 4,762 stroke or transient ischaemic attack patients treated with clopidogrel. ${ }^{132}$ Thirteen out of these 15 studies included Asian, mostly Chinese, patients ( $n=4,009,84 \%$ ). Another very recent study investigated the impact of glycaemic control on clopidogrel responsiveness in Chinese patients. Data showed that treatment with clopidogrel was beneficial only in non-carriers of CYP2C19 loss-of-function alleles who maintained good glycaemic control. ${ }^{133}$ Comparable data for non-Asian patients are scant and direct empirical evidence for anti-platelet non-responsiveness in stroke recurrence is generally scarce as the measurement of platelet reactivity in stroke patients is not commonly performed in clinical practice. $^{129}$

\section{How Targeting vWF could Overcome the Pitfalls of Current Stroke Prevention and Treatment}

\section{von Willebrand Factor Targeting in Acute Stroke}

Several novel pharmacological approaches have been tested to overcome the difficulties of current stroke therapy, but with ambiguous results. Desmoteplase and de-fibrogenating agents were drug candidates promising to overcome the issue of rtPA-resistant thrombi which showed encouraging results in terms of reperfusion rates and disability, but still failed due to an increase in intra-cerebral bleeding. ${ }^{134}$ Therefore, a new therapeutic approach that restores cerebral blood flow without increasing bleeding complications is a desirable goal not yet attained, and vWF-targeting strategies might meet this need. Supporting evidence for the mechanistic rationale of therapeutic vWF inhibition in stroke comes from pre-clinical studies investigating the pathophysiologic role of GPIb-vWF axis in cerebral ischaemia. ${ }^{12}$ The contribution of vWF to the architecture of arterial thrombi formed under shear stress and their resistance to therapeutic dissolution has recently been illustrated in animal models of acute ischaemic stroke. While thrombi were resistant to conventional anti-thrombotic agents and fibrinolysis because of 'protective' vWF-platelet aggregates forming their external layer, disruption of GPIb-vWF interactions and platelet cross-linking by vWF inhibition dissolved thrombi and restored cerebral blood flow. ${ }^{135-137}$ Furthermore, treatment with recombinant ADAMTS13 reduced neurotoxicity induced by rtPA; in a mouse model, recombinant ADAMTS13 in combination with rtPA significantly reduced infarct volume compared with mice treated with rtPA only, reflecting a neuroprotective effect largely mediated by specific NMDA receptor blockade reducing excitotoxic cell death. ${ }^{138}$

As the GPIb-vWF axis is haemostatically important, primarily under high shear conditions, physiological haemostasis under low or moderate shear conditions should theoretically not be impaired by vWF blockade. This is in agreement with available safety data on serious bleeding events from pre-clinical and clinical studies investigating vWF inhibitors in healthy volunteers ${ }^{139}$ and in patients with thrombotic thrombocytopenic purpura ${ }^{140-142}$ and von Will- ebrand disease. ${ }^{143}$ Stenotic cerebrovascular arteries leading to increased blood velocity and shear stress are pre-dilected sites for thrombus embolization and total occlusion with resulting cerebral ischaemia. While rtPA promotes thrombolysis within all blood vessels, vWF-targeting strategies should act selectively at stenotic, vWF-rich sites. Direct vWF-blocking agents showed promising results in pre-clinical studies. The nano-body, caplacizumab (ALX-0081), reduced brain infarct size in guinea pigs by GPIb-vWF blockade with no bleeding complications. ${ }^{136}$ Furthermore, ADAMTS13-mediated cleavage of ultra-large vWF, which reduces adhesion of platelets and clot formation, has been assessed. Recombinant ADAMTS13 successfully restored cerebral blood flow and reduced cerebral infarct size up to 1 hour after occlusion with no increase in cerebral haemorrhage in a mouse model with rtPA-resistant, vWF-rich middle cerebral artery thrombi. ${ }^{137}$ However, both studies only investigated drug administration up to 1 hour after occlusion -a time window that does not reflect a clinical setting and therefore the critical point of the narrow time window in stroke treatment has not been assessed by these studies.

\section{Sample Size Considerations in Targeting von Willebrand Factor in Primary Stroke Prevention}

Recently, the large COMPASS trial, including more than 27,000 patients, showed a risk reduction for stroke when rivaroxaban was combined with aspirin versus aspirin alone, while rivaroxaban alone was not significantly better. ${ }^{144}$ The low number of stroke events in this patient population despite pre-existent stable cardiovascular disease requiring high patient numbers to demonstrate benefit is not ideal for a first development program, as a sample size of more than $2 \times 4,000$ patients would be required to test the efficacy a new treatment such as an vWF inhibitor.

\section{Targeting von Willebrand Factor in Secondary Stroke Prevention}

vWF might not only be an attractive target in acute stroke treatment but also in secondary stroke prevention, particularly if aimed at a sub-population at high risk of stroke recurrence that could especially benefit from a more potent anti-platelet therapy with a better risk profile.

While multiple agents representing several drug classes have proven benefit in coronary artery disease, including heparin, GPIIb/IIIa inhibitors, P2Y12-receptor antagonists, such as ticagrelor and prasugrel, as well as the thrombinreceptor antagonist vorapaxar, none of these drugs have improved a benefit:risk ratio for stroke prevention superior to aspirin.

\section{Ticagrelor, Prasugrel and Vorapaxar Did Not Improve} Outcome in Stroke Prevention

The use of ticagrelor, a more potent third-generation adenosine diphosphate-receptor blocker, was not superior to aspirin in reducing the rate of stroke recurrence, myocardial infarction or death within 90 days in a large prospective trial involving 13,199 patients with a non-severe ischaemic stroke or high-risk transient ischaemic attack, and thus is 
currently not recommended. ${ }^{145}$ Nevertheless, sub-group analysis $(n=3,906)$ suggest that Asian patients or those suffering from LAA could potentially benefit from the more potent platelet inhibition by ticagrelor. ${ }^{146}$

Prasugrel is contraindicated in patients with a history of cerebrovascular events based on results from the TRITONTIMI trial. This study compared prasugrel to clopidogrel in more than 13,600 patients with acute coronary syndrome and found a significant harm from prasugrel among those with a history of stroke or transient ischaemic attack. ${ }^{10}$ Recent data from a Japanese study confirmed the lack of benefit of prasugrel in comparison to clopidogrel in 3,747 non-cardioembolic stroke patients. ${ }^{147}$

Likewise, the thrombin-receptor antagonist vorapaxar is contraindicated in patients with prior stroke, because it increases the risk of intra-cranial haemorrhage in this population (HR, 2.52; CI, 1.46-4.36) ${ }^{11}$ without improving the rate of ischaemic vascular events. However, more recent data suggest that vorapaxar may reduce the risk of primary ischaemic stroke in patients with atherosclerosis but without clinically evident cerebrovascular disease when used as mono-therapy rather than in addition to standard antiplatelet therapy aspirin or clopidogrel. ${ }^{148}$

\section{Dual Anti-Platelet Therapy}

The use of dual anti-platelet therapy with clopidogrel and aspirin in secondary stroke prevention is considered beneficial only in the first 90 days because it was shown to cause harm in the form of major bleeding thereafter. ${ }^{149,150}$

These data highlight the need for novel anti-thrombotic strategies that are safer and more effective than available anti-platelet agents, especially regarding long-term prevention of stroke recurrence. Aspirin reduced the risk of early recurrent stroke (i.e. in the first 6 weeks from the index event) in a recent longitudinal study investigating individual patient data from all available controlled trials on use of aspirin versus control in secondary prevention after transient ischaemic attack or ischaemic stroke, in contrast, its use had no effect on the 12-week risk of stroke recurrence. ${ }^{123}$ Taken together, vWF-targeting agents could possibly overcome the pitfalls of current stroke therapy and prevention, but to date such agents have only been tested in animal models of stroke.

\section{von Willebrand Factor Inhibitors in Ischaemic Stroke and Target Populations}

There are three potential targets that mediate vWF-dependent thrombus formation. These are vWF-GPIb, vWF-collagen and vWF-GPIIbIIIa. However, animal models showed, that while collagen- and GPIb-binding are essential in stroke development, GPIIbIIIa interactions are without any relevance. ${ }^{151}$ The insignificant effect of vWF-GPIIbIIIa binding in stroke is therefore compatible with the negative clinical trials of the GPIIbIIIa receptor inhibitor Abciximab. ${ }^{8}$ Thus, only GPIb-vWF and collagen-vWF blockers are in the focus of drug development for stroke. In previous years, vWF inhibitors have been investigated in various pre-clinical and clin- ical studies (-Table 3 and -Supplementary Table S3, available in the online version). Several substances have been evaluated in animal models, of which five have been tested in humans. Molecules suitable for targeting vWF include antibodies, nano-bodies, aptamers and a vWF antagonist derived from snake venom. Mechanisms of action are described in - Fig. $\mathbf{1}$.

Nano-bodies are fragments of antibodies with lower molecular mass and size, which enable better permeability and quicker elimination. Furthermore, nano-bodies are less likely to cause cytotoxicity triggered by complement activation, as they lack the Fc-region. ${ }^{152}$ The first anti-vWF-nanobody will likely be approved for the treatment of TTP, due to positive results of recent Phase II/III trials. ${ }^{46,153}$

Another approach to target specific molecules is facilitated by aptamer technology. Aptamers are molecules composed of single stranded nucleic acids folded into a specific tertiary structure, that specifically bind to their target, e.g., proteins, enzymes, viruses or receptors. ${ }^{154}$ Methods used to produce aptamers are based on the principle of repetitive amplification and selection processes in vitro, producing molecules with high affinity. ${ }^{154}$ In contrast to antibody production, chemical synthesis of aptamers does not require a biological system (e.g. Chinese hamster ovary cells) for production. Various in vitro studies have proven the capacity of anti-vWF aptamers in inhibiting vascular platelet adhesion only under high shear and one clinical trial has shown that an anti-vWF aptamer is capable of significantly reducing micro-embolic signals in the cerebral circulation immediately following carotid endarterectomy. ${ }^{155}$

\section{Target Populations That May Benefit from von Willebrand Factor Inhibition}

As vWF-platelet interactions are promoted by arterial shear stress, it is conceivable that patients with conditions, in which vWF likely plays a key role in thrombus formation, would in particular stand to gain benefit from therapeutic vWF blockade. This may include patients with stenotic LAA, those who have undergone carotid stenting, patients with persistently elevated vWF levels after an ischaemic event and those unresponsive to fibrinolytic or anti-platelet therapy.

Whether vWF is independently associated with nonresponsiveness to conventional anti-platelet drugs across the heterogeneous population of ischaemic stroke patients or is rather a major contributing factor in specific stroke subtypes or in the presence of distinct co-morbidities is as yet unclear and needs further investigation.

The proportion of stroke patients unresponsive to aspirin and clopidogrel measured by whole blood aggregometry, however, is substantial. ${ }^{129}$ Interference with platelet-activating pathways independent of cyclooxygenase and adenosine diphosphate receptors certainly constitutes one promising therapeutic target. In this context, the association between high vWF levels and aspirin unresponsiveness is interesting. ${ }^{130}$ The question whether and to what extent vWF inhibition may overcome high on-treatment platelet reactivity in ischaemic stroke, however, has not yet been clearly answered. 
Table 3 Human studies of investigational von Willebrand inhibitors

\begin{tabular}{|c|c|c|c|c|c|}
\hline \multicolumn{6}{|l|}{ Human studies } \\
\hline Name & Type & Target & $\begin{array}{l}\text { Underlying } \\
\text { disease }\end{array}$ & Outcome & Reference \\
\hline \multirow[t]{3}{*}{ ARC1779 } & \multirow[t]{3}{*}{$\begin{array}{l}\text { DNA/RNA } \\
\text { aptamer }\end{array}$} & \multirow[t]{3}{*}{ GPIbo-vWF } & vWD type II & $\begin{array}{l}\text { Desmopressin- } \\
\text { induced } \\
\text { thrombocytopenia }\end{array}$ & $\begin{array}{l}\text { Jilma et al }{ }^{143} \\
\text { Jilma-Stohlawetz et al }\end{array}$ \\
\hline & & & $\begin{array}{l}\text { Acquired and } \\
\text { congenital TTP }\end{array}$ & $\begin{array}{l}\text { Pharmacokinetics, } \\
\text { pharmacodynamics, } \\
\text { safety }\end{array}$ & $\begin{array}{l}\text { Jilma-Stohlawetz et al }{ }^{188} \\
\text { Cataland et al }{ }^{142} \\
\text { Jilma-Stohlawetz et al }{ }^{189}\end{array}$ \\
\hline & & & Carotid stenosis & $\begin{array}{l}\text { Inhibition of micro- } \\
\text { embolic signals up to } \\
3 \text { h after carotid } \\
\text { endarterectomy }\end{array}$ & Markus et al $^{155}$ \\
\hline AJW200 & $\begin{array}{l}\text { Monoclonal } \\
\text { antibody }\end{array}$ & GPIbo-vWF & $\begin{array}{l}\text { Healthy } \\
\text { volunteers }\end{array}$ & Safety & Machin et al ${ }^{190}$ \\
\hline rADAMTS13 & $\begin{array}{l}\text { Recombinant } \\
\text { ADAMTS13 }\end{array}$ & $\begin{array}{l}\text { Ultra-large vWF } \\
\text { multimers }\end{array}$ & Congenital TTP & Safety & Scully et al ${ }^{191}$ \\
\hline Anfibatide & $\begin{array}{l}\text { Snake venom } \\
\text { derived }\end{array}$ & GPIb $\alpha-v W F$ & $\begin{array}{l}\text { Healthy } \\
\text { volunteers }\end{array}$ & Safety & Hou et $\mathrm{al}^{192}$ \\
\hline $\begin{array}{l}\text { ALX-0081 } \\
\text { (caplacizumab) }\end{array}$ & Nano-body & GPIba-vWF & Acquired TTP & $\begin{array}{l}\text { Time to normaliza- } \\
\text { tion of platelet } \\
\text { count; number of } \\
\text { exacerbations and } \\
\text { relapses }\end{array}$ & Peyvandi et al ${ }^{46}$ \\
\hline
\end{tabular}

Abbreviations: GP, glycoprotein; TTP, thrombotic thrombocytopenic purpura; vWD, von Willebrand disease; vWF, von Willebrand factor.

Future studies need to define populations that are prone to developing vWF-mediated stroke and identify stroke sub-types that are sensitive to vWF inhibition to further refine the strategy for the clinical development of such agents.
Patients with Stroke Caused by von Willebrand FactorRich Thrombi

Early re-canalization and vessel re-opening is vital to achieving good outcome after ischaemic stroke. Attempts at vessel re-canalization by thrombolytics, however, fail in the large
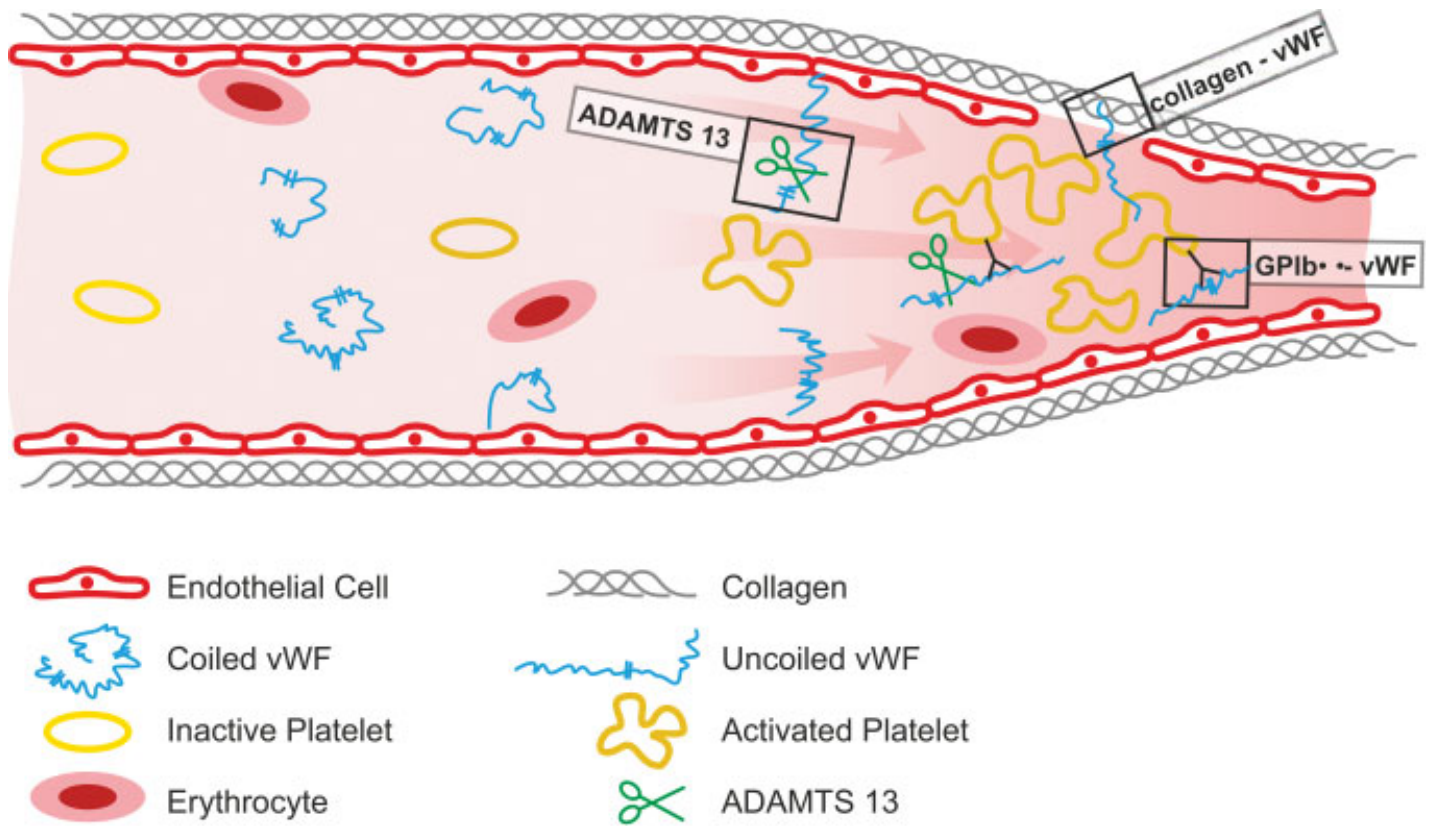

Fig. 1 Scheme of von Willebrand factor (vWF) under high shear rates. Legend: Different mechanisms of actions of investigational von Willebrand factor inhibitors are described, i.e., GPIb $\alpha$-vWF, ultra-large vWF multimers (recombinant ADAMTS13) and collagen-vWF. GP, glycoprotein. 
majority of patients. ${ }^{106}$ Response to lysis and rates of early re-canalization by rtPA are particularly low in large vessel disease. One reason for this might be functional resistance of clots to therapeutic fibrinolysis. ${ }^{110}$

Lytic susceptibility depends on the specific structural aspects of the clot. vWF-rich thrombi formed under shear stress were shown to be resistant to conventional recombinant tissue-type plasminogen activator in both stroke and myocardial infarction. ${ }^{156,157}$ A substantial fraction of thrombi retrieved from stroke patients contain high levels of vWF. vWF-rich thrombi are resistant to conventional rtPA, but are however sensitive to vWF cleavage by early infusion of ADAMTS13. Higher baseline ADAMTS13 levels and activity $>75 \%$ in patients with acute stroke predict re-canalization success at 2 hours. ${ }^{158}$ Blocking the GPIb-vWF axis on top of therapeutic plasminogen activation could be of therapeutic benefit because it may overcome lysis resistance in selected patients. In this context, the identification of vWF-rich thrombi by computed tomography or magnetic resonance imaging to guide treatment could become an interesting future approach for more individualized stroke therapy. ${ }^{159}$

\section{Patients with Large Artery Atherosclerosis}

In patients with 50 to $99 \%$ stenosis of a large intra-cranial artery, the annual rate of ischaemic stroke ranges between 6 and $15 \%$ despite standard medical treatment with current anti-platelet agents. ${ }^{160,161}$ Particularly, patients with severe ( $\geq 70 \%$ ) or haemodynamically significant stenosis, those with ischaemic symptoms, and women with symptomatic intra-cranial arterial stenosis are at high risk of stroke. ${ }^{160,162}$ Intra-cranial stenting is not beneficial in these patients according to the disappointing results from two large randomized trials. ${ }^{161,163}$ Aspirin is usually used for long-term stroke prevention. In an ex vivo study on human atherosclerotic plaques, however, acetylsalicylic acid in contrast to a GPIb inhibitor failed to inhibit plaque-induced platelet thrombus formation under arterial flow conditions. ${ }^{89}$ This may at least partly explain the continuing high rates of ischaemic stroke despite treatment with aspirin in patients with atherosclerotic stenosis of a large intra-cranial artery. ${ }^{89}$ Given the high rates of ischaemic events in those patients, however, novel therapeutic strategies would be desirable.

Following results from a previous meta-analysis comparing incidence and sub-types of stroke between Chinese and European patients, the prevalence of LAA is significantly higher in Chinese patients. ${ }^{3}$ Similarly, LAA sub-type of stroke was the most common stroke aetiology found in the Korean stroke registry. ${ }^{164}$

Increasing insights into vWF-mediated platelet-endothelium interactions at the site of arteriosclerotic lesions suggest that patients with intra-cranial major artery arteriosclerosis could possibly benefit from (add-on) treatment with a vWF-blocking agent. Plaque-associated thrombus formation is critically dependent on blood-borne vWF, offering the opportunity for a vWF-targeting approach.

The significance of vWF in human atherogenesis, however, remains under investigation. High levels of vWF in LAA patients, ${ }^{87}$ the strong association of vWF with the extent of atherosclerotic plaques and the inverse relation between plasma ADAMTS13 activity and the risk of both cerebroand cardiovascular disease $\mathrm{e}^{54,165}$ reported by clinical studies yet suggest that vWF may serve a promising therapeutic target in large vessel disease.

In animal models of atherosclerosis, both the inhibition and deletion of vWF successfully reduced inflammation, plaque size and platelet adhesion, ${ }^{166-168}$ while the deletion of ADAMTS13 had opposite effects. ${ }^{169,170}$ Human clinical data on the impact of vWF inhibition on atherosclerosis are not available.

\section{Secondary Prevention after Endarterectomy, Angioplasty and Stenting}

Lifelong administration of aspirin is recommended after carotid endarterectomy. To date, endarterectomy with stenting is recommended only in patients with symptomatic extra-cranial internal carotid artery atherosclerotic disease without total occlusion. Restenosis, however, may occur in up to $12 \%$ of patients within the first 24 months. ${ }^{171}$ Data from a 2003 Cochrane review furthermore suggest that the use of anti-platelet agents after carotid endarterectomy has no effects on all-cause death but may increase the risk of bleeding. ${ }^{172}$

In patients who undergo carotid artery stenting, dual antiplatelet treatment is commonly administered for 6 weeks to limit the risk for thromboembolic complications and restenosis. ${ }^{173}$ Evidence for this therapeutic approach, however, is yet limited and restenosis rates range between 0.5 and $5 \%$ for early and up to $7 \%$ at 10 years for late events. Early restenosis results from procedure-related vascular injury with subsequent intimal hyperplasia and occurs more frequently in women, diabetics and patients with neck irradiation. ${ }^{174-176}$

Endovascular procedures induce damage and activation of the endothelial layer with subsequent release of inflammatory markers including vWF release, ${ }^{177,178}$ which may contribute to the risk of early and late thromboembolic complications. Platelet activation during carotid endarterectomy even occurs despite the use of anti-platelet treatment. ${ }^{179}$

The occurrence of stent restenosis was significantly associated with persistently elevated vWF levels in a prospective study investigating the relation between vWF plasma levels and restenosis after carotid artery stenting within the first 6 months. ${ }^{180}$ It is conceivable, that additional vWF blockade on top of conventional anti-platelet therapy may provide superior anti-thrombotic effects at the site of endothelial damage after endarterectomy or stent placement by impairing localized vWF-driven platelet aggregation and subsequent thrombus formation. In this context, vWF inhibition by the aptamer ARC 1779 significantly reduced sonographically detectable micro-embolic signals within 3 hours after carotid endarterectomy in a clinical trial on 36 patients with carotid stenosis. ${ }^{155}$ Likewise, in rat models, vWF inhibition significantly decreased platelet adhesion, intimal hyperplasia, stenosis and thrombosis after carotid endarterectomy. ${ }^{181}$ Together, these data support a rationale of vWF blockade after endovascular procedures. 


\section{Asian Population}

The rationale for why Asian individuals in particular might benefit from an anti-vWF approach is based upon several pieces of evidence. In China, approximately 2.4 million people suffer from stroke each year, ${ }^{182}$ which constitutes the highest rate worldwide. Chinese patients have lower mean age at stroke onset ${ }^{3}$ and it is especially noteworthy that intra-cranial atherosclerosis, a relatively rare form of cerebrovascular disease in Caucasians, is highly prevalent in young Chinese stroke patients. ${ }^{183}$

This disproportionally high rate of intra-cranial atherosclerosis, the high prevalence of ischaemic stroke overall and the large percentage of LAA stroke sub-types ${ }^{3}$ in Asian countries, makes Asian patients probably suitable for a more potent anti-platelet strategy. Furthermore, a sub-group analysis of outcome data in the SOCRATES study ${ }^{146}$ suggested that platelet inhibition may translate into a more pronounced clinical benefit in Asians. Hence, Asians may represent a particularly suitable population to test the benefits of platelet inhibition by targeting vWF-mediated platelet adhesion and aggregation. In addition, the high number of CYP2C19 alleles carriers in the Chinese population $^{131}$ and the associated poor metabolic activation of and hence poor responsiveness to clopidogrel especially in patients with poor glycaemic control, support the rationale for a vWF-targeting approach.

\section{Conclusion}

The rationale for vWF as a potential target in stroke comes from four bodies of evidence: animal models, that help us to understand the pathogenesis of stroke and give rise to the concept of vWF-targeting strategies; epidemiologic data demonstrating that plasma levels of vWF predict the occurrence and recurrence of stroke; genetic studies that establish an association between vWF levels and stroke risk on genomic levels; and lessons learned from patients with vWF disorders that showed the crucial role of vWF in atherothrombosis and stroke. However, randomized clinical trials with vWF inhibitors are needed to ultimately demonstrate the relevance of blocking $\mathrm{vWF}$ for the prevention or treatment of ischaemic stroke in this patient population.

Conceivably, identification of vWF-rich thrombi with high-resolution imaging techniques could help to stratify patients susceptible for an anti-vWF approach in the acute setting. Individualized acute stroke treatment could improve re-canalization rates with the maintenance of acceptable bleeding rates.

Also, for primary and secondary stroke prevention, targeting high-risk populations will likely improve the benefit: risk ratio. Therefore, sub-populations of patients need yet to be defined that might best respond to vWF inhibition. The contemporary understanding of stroke as a clinically and biologically diverse entity led to the consideration of a more individualized approach to pharmacotherapy and endovascular interventions for care of patients with stroke, based on risk stratification and careful differentiation between patient sub-groups. However, patients' risk stratification should probably not only be based on pathophysiologic mechanism but also on the genetic determinants and biomarkers that reflect increased risk. Specifically, patients with a high degree of LAA and CYP2C19 loss of function alleles carriers might be ideal candidates for a vWF targeting approach.

\section{Funding}

This study was funded by the Austrian Science Fund FWF_F 5404-B21 (Special Research Program, Cellular Mediators Linking Inflammation and Thrombosis).

\section{Conflict of Interest}

J.G. is the founder of Band Therapeutics, a 'virtual' biotech company that was established to discover and develop novel biotherapeutics targeting von Willebrand factor. Other authors declare no conflict of interest.

\section{References}

1 Lozano R, Naghavi M, Foreman K, et al. Global and regional mortality from 235 causes of death for 20 age groups in 1990 and 2010: a systematic analysis for the Global Burden of Disease Study 2010. Lancet 2012;380(9859):2095-2128

2 Benjamin EJ, Blaha MJ, Chiuve SE, et al; American Heart Association Statistics Committee and Stroke Statistics Subcommittee. Heart Disease and Stroke Statistics-2017 update: a report from the American Heart Association. Circulation 2017;135(10): e146-e603

3 Tsai CF, Thomas B, Sudlow CL. Epidemiology of stroke and its subtypes in Chinese vs white populations: a systematic review. Neurology 2013;81(03):264-272

4 Heuschmann PU, Di Carlo A, Bejot Y, et al; European Registers of Stroke (EROS) Investigators. Incidence of stroke in Europe at the beginning of the 21st century. Stroke 2009;40(05): 1557-1563

5 Feigin VL, Forouzanfar MH, Krishnamurthi R, et al; Global Burden of Diseases, Injuries, and Risk Factors Study 2010 (GBD 2010) and the GBD Stroke Experts Group. Global and regional burden of stroke during 1990-2010: findings from the Global Burden of Disease Study 2010. Lancet 2014;383(9913):245-254

6 Mozaffarian D, Benjamin EJ, Go AS, et al; Writing Group Members; American Heart Association Statistics Committee; Stroke Statistics Subcommittee. Executive summary: Heart Disease and Stroke Statistics-2016 update: a report from the American Heart Association. Circulation 2016;133(04):447-454

7 Di Carlo A. Human and economic burden of stroke. Age Ageing 2009;38(01):4-5

8 Adams HP Jr, Effron MB, Torner J, et al; AbESTT-II Investigators. Emergency administration of abciximab for treatment of patients with acute ischemic stroke: results of an international phase III trial: Abciximab in Emergency Treatment of Stroke Trial (AbESTT-II). Stroke 2008;39(01):87-99

9 Ciccone A, Motto C, Abraha I, Cozzolino F, Santilli I. Glycoprotein IIb-IIIa inhibitors for acute ischaemic stroke. Cochrane Database Syst Rev 2014;(03):CD005208

10 Montalescot G, Wiviott SD, Braunwald E, et al; TRITON-TIMI 38 investigators. Prasugrel compared with clopidogrel in patients undergoing percutaneous coronary intervention for ST-elevation myocardial infarction (TRITON-TIMI 38): double-blind, randomised controlled trial. Lancet 2009;373(9665):723-731

11 Morrow DA, Alberts MJ, Mohr JP, et al; Thrombin Receptor Antagonist in Secondary Prevention of Atherothrombotic Ischemic Events-TIMI 50 Steering Committee and Investigators. Efficacy and safety of vorapaxar in patients with prior ischemic stroke. Stroke 2013;44(03):691-698 
12 Denorme F, De Meyer SF. The VWF-GPIb axis in ischaemic stroke: lessons from animal models. Thromb Haemost 2016;116(04): 597-604

13 Adams HP Jr, Bendixen BH, Kappelle LJ, et al. Classification of subtype of acute ischemic stroke. Definitions for use in a multicenter clinical trial. TOAST. Trial of Org 10172 in Acute Stroke Treatment. Stroke 1993;24(01):35-41

14 Petty GW, Brown RD Jr, Whisnant JP, Sicks JD, O'Fallon WM, Wiebers DO. Ischemic stroke subtypes: a population-based study of functional outcome, survival, and recurrence. Stroke 2000;31(05):1062-1068

15 Koppelman SJ, van Hoeij M, Vink T, et al. Requirements of von Willebrand factor to protect factor VIII from inactivation by activated protein C. Blood 1996;87(06):2292-2300

16 Hannah MJ, Williams R, Kaur J, Hewlett LJ, Cutler DF. Biogenesis of Weibel-Palade bodies. Semin Cell Dev Biol 2002;13(04): 313-324

17 Schoergenhofer C, Matzneller P, Mußbacher M, et al. Colistin dampens fibrinolysis and endothelial activation during endotoxaemia. A randomised, double blind trial. Thromb Haemost 2017;117(09):1714-1721

18 Jilma B, Pernerstorfer T, Dirnberger E, et al. Effects of histamine and nitric oxide synthase inhibition on plasma levels of von Willebrand factor antigen. J Lab Clin Med 1998;131(02): 151-156

19 Siller-Matula JM, Miller I, Gemeiner M, et al. Continuous thrombin infusion leads to a bleeding phenotype in sheep. Thromb Res 2012;130(02):226-236

20 Derhaschnig U, Pachinger C, Schweeger-Exeli I, Marsik C, Jilma B. Blockade of GPIIb/IIIa by eptifibatide and tirofiban does not alter tissue factor induced thrombin generation in human endotoxemia. Thromb Haemost 2003;90(06):1054-1060

21 Reiter RA, Mayr F, Blazicek H, et al. Desmopressin antagonizes the in vitro platelet dysfunction induced by GPIIb/IIIa inhibitors and aspirin. Blood 2003;102(13):4594-4599

22 Wagner DD, Saffaripour S, Bonfanti R, et al. Induction of specific storage organelles by von Willebrand factor propolypeptide. Cell 1991;64(02):403-413

23 Sing CE, Alexander-Katz A. Elongational flow induces the unfolding of von Willebrand factor at physiological flow rates. Biophys J 2010;98(09):L35-L37

24 Marx I, Christophe OD, Lenting PJ, et al. Altered thrombus formation in von Willebrand factor-deficient mice expressing von Willebrand factor variants with defective binding to collagen or GPIIbIIIa. Blood 2008;112(03):603-609

25 Petri B, Broermann A, Li H, et al. von Willebrand factor promotes leukocyte extravasation. Blood 2010;116(22):4712-4719

26 De Meyer GR, Hoylaerts MF, Kockx MM, Yamamoto H, Herman AG, Bult H. Intimal deposition of functional von Willebrand factor in atherogenesis. Arterioscler Thromb Vasc Biol 1999;19 (10):2524-2534

27 Trillo AA, Prichard RW. Early endothelial changes in experimental primate atherosclerosis. Lab Invest 1979;41(04):294-302

28 Möller K, Adolph O, Grünow J, et al. Mechanism and functional impact of CD40 ligand-induced von Willebrand factor release from endothelial cells. Thromb Haemost 2015;113(05): 1095-1108

29 Nguyen TC, Liu A, Liu L, et al. Acquired ADAMTS-13 deficiency in pediatric patients with severe sepsis. Haematologica 2007;92 (01):121-124

30 Methia N, André P, Denis CV, Economopoulos M, Wagner DD. Localized reduction of atherosclerosis in von Willebrand factordeficient mice. Blood 2001;98(05):1424-1428

31 van Galen KP, Tuinenburg A, Smeets EM, Schutgens RE. Von Willebrand factor deficiency and atherosclerosis. Blood Rev 2012;26(05):189-196

32 Getz GS, Reardon CA. Animal models of atherosclerosis. Arterioscler Thromb Vasc Biol 2012;32(05):1104-1115
33 Bongers TN, de Maat MP, van Goor ML, et al. High von Willebrand factor levels increase the risk of first ischemic stroke: influence of ADAMTS13, inflammation, and genetic variability. Stroke 2006;37(11):2672-2677

34 Folsom AR, Rosamond WD, Shahar E, et al; The Atherosclerosis Risk in Communities (ARIC) Study Investigators. Prospective study of markers of hemostatic function with risk of ischemic stroke. Circulation 1999;100(07):736-742

35 Williams SR, Hsu FC, Keene KL, et al; GARNET (The Genomics and Randomized Trials Network) Collaborative Research Group. Genetic drivers of von Willebrand factor levels in an ischemic stroke population and association with risk for recurrent stroke. Stroke 2017;48(06):1444-1450

36 Menih M, Križmarić M, Hojs Fabjan T. Clinical role of von Willebrand factor in acute ischemic stroke. Wien Klin Wochenschr 2017;129(13-14):491-496

37 Kraft P, Drechsler C, Gunreben I, et al. Von Willebrand factor regulation in patients with acute and chronic cerebrovascular disease: a pilot, case-control study. PLoS One 2014;9(06):e99851

38 Samai A, Monlezun D, Shaban A, et al. Von Willebrand factor drives the association between elevated factor VIII and poor outcomes in patients with ischemic stroke. Stroke 2014;45(09): 2789-2791

39 Bath PM, Blann A, Smith N, Butterworth RJ. Von Willebrand factor, P-selectin and fibrinogen levels in patients with acute ischaemic and haemorrhagic stroke, and their relationship with stroke subtype and functional outcome. Platelets 1998;9(3-4):155-159

40 Carter AM, Catto AJ, Mansfield MW, Bamford JM, Grant PJ. Predictive variables for mortality after acute ischemic stroke. Stroke 2007;38(06):1873-1880

41 Favaloro EJ, Pasalic L, Curnow J. Laboratory tests used to help diagnose von Willebrand disease: an update. Pathology 2016;48 (04):303-318

42 Eikenboom J, Federici AB, Dirven RJ, et al; MCMDM-1VWD Study Group. VWF propeptide and ratios between VWF, VWF propeptide, and FVIII in the characterization of type 1 von Willebrand disease. Blood 2013;121(12):2336-2339

43 Kleinschnitz C, De Meyer SF, Schwarz T, et al. Deficiency of von Willebrand factor protects mice from ischemic stroke. Blood 2009;113(15):3600-3603

44 Zhao BQ, Chauhan AK, Canault M, et al. von Willebrand factorcleaving protease ADAMTS13 reduces ischemic brain injury in experimental stroke. Blood 2009;114(15):3329-3334

45 Sanders YV, Eikenboom J, de Wee EM, et al; WiN Study Group. Reduced prevalence of arterial thrombosis in von Willebrand disease. J Thromb Haemost 2013;11(05):845-854

46 Peyvandi F, Scully M, Kremer Hovinga JA, et al; TITAN Investigators. Caplacizumab for acquired thrombotic thrombocytopenic purpura. N Engl J Med 2016;374(06):511-522

47 Catto AJ, Carter AM, Barrett JH, Bamford J, Rice PJ, Grant PJ. von Willebrand factor and factor VIII: $C$ in acute cerebrovascular disease. Relationship to stroke subtype and mortality. Thromb Haemost 1997;77(06):1104-1108

48 Qizilbash N, Duffy S, Prentice CR, Boothby M, Warlow C. Von Willebrand factor and risk of ischemic stroke. Neurology 1997; 49(06):1552-1556

49 Hanson E, Jood K, Karlsson S, Nilsson S, Blomstrand C, Jern C. Plasma levels of von Willebrand factor in the etiologic subtypes of ischemic stroke. J Thromb Haemost 2011;9(02):275-281

50 van Schie MC, DE Maat MP, Dippel DW, et al. von Willebrand factor propeptide and the occurrence of a first ischemic stroke. J Thromb Haemost 2010;8(06):1424-1426

51 McCabe DJ, Murphy SJ, Starke R, et al. Relationship between ADAMTS13 activity, von Willebrand factor antigen levels and platelet function in the early and late phases after TIA or ischaemic stroke. J Neurol Sci 2015;348(1-2):35-40

52 Tobin WO, Kinsella JA, Kavanagh GF, et al. Profile of von Willebrand factor antigen and von Willebrand factor propeptide in 
an overall TIA and ischaemic stroke population and amongst subtypes. J Neurol Sci 2017;375:404-410

53 Andersson HM, Siegerink B, Luken BM, et al. High VWF, low ADAMTS13, and oral contraceptives increase the risk of ischemic stroke and myocardial infarction in young women. Blood 2012; 119(06):1555-1560

54 Sonneveld MA, de Maat MP, Portegies ML, et al. Low ADAMTS13 activity is associated with an increased risk of ischemic stroke. Blood 2015;126(25):2739-2746

55 Smith FB, Lee AJ, Fowkes FG, Price JF, Rumley A, Lowe GD. Hemostatic factors as predictors of ischemic heart disease and stroke in the Edinburgh Artery Study. Arterioscler Thromb Vasc Biol 1997;17(11):3321-3325

56 Tzoulaki I, Murray GD, Lee AJ, Rumley A, Lowe GD, Fowkes FG. Relative value of inflammatory, hemostatic, and rheological factors for incident myocardial infarction and stroke: the Edinburgh Artery Study. Circulation 2007;115(16): 2119-2127

57 Bevan S, Traylor M, Adib-Samii P, et al. Genetic heritability of ischemic stroke and the contribution of previously reported candidate gene and genomewide associations. Stroke 2012;43 (12):3161-3167

58 Traylor M, Farrall M, Holliday EG, et al; Australian Stroke Genetics Collaborative, Wellcome Trust Case Control Consortium 2 (WTCCC2); International Stroke Genetics Consortium. Genetic risk factors for ischaemic stroke and its subtypes (the METASTROKE collaboration): a meta-analysis of genome-wide association studies. Lancet Neurol 2012;11(11):951-962

59 Malik R, Traylor M, Pulit SL, et al; ISGC Analysis Group; METASTROKE collaboration; Wellcome Trust Case Control Consortium 2 (WTCCC2); NINDS Stroke Genetics Network (SiGN). Lowfrequency and common genetic variation in ischemic stroke: the METASTROKE collaboration. Neurology 2016;86(13): $1217-1226$

60 Auer PL, Nalls M, Meschia JF, et al; National Heart, Lung, and Blood Institute Exome Sequencing Project. Rare and coding region genetic variants associated with risk of ischemic stroke: the NHLBI Exome Sequence Project. JAMA Neurol 2015;72(07): 781-788

61 Network NSG; NINDS Stroke Genetics Network (SiGN); International Stroke Genetics Consortium (ISGC). Loci associated with ischaemic stroke and its subtypes (SiGN): a genome-wide association study. Lancet Neurol 2016;15(02):174-184

62 Dichgans M, Malik R, König IR, et al; METASTROKE Consortium; CARDIoGRAM Consortium; C4D Consortium; International Stroke Genetics Consortium. Shared genetic susceptibility to ischemic stroke and coronary artery disease: a genome-wide analysis of common variants. Stroke 2014;45(01):24-36

63 Van Schie MC, Wieberdink RG, Koudstaal PJ, et al. Genetic determinants of von Willebrand factor plasma levels and the risk of stroke: the Rotterdam Study. J Thromb Haemost 2012;10 (04):550-556

64 Fernández-Cadenas I, Del Río-Espínola A, Giralt D, et al. IL1B and VWF variants are associated with fibrinolytic early recanalization in patients with ischemic stroke. Stroke 2012;43(10): 2659-2665

65 de Lange M, Snieder H, Ariëns RA, Spector TD, Grant PJ. The genetics of haemostasis: a twin study. Lancet 2001;357 (9250):101-105

66 Smith NL, Chen MH, Dehghan A, et al; Wellcome Trust Case Control Consortium. Novel associations of multiple genetic loci with plasma levels of factor VII, factor VIII, and von Willebrand factor: The CHARGE (Cohorts for Heart and Aging Research in Genome Epidemiology) Consortium. Circulation 2010;121(12): 1382-1392

67 Huffman JE, de Vries PS, Morrison AC, et al. Rare and lowfrequency variants and their association with plasma levels of fibrinogen, FVII, FVIII, and vWF. Blood 2015;126(11):e19-e29
68 van Loon J, Dehghan A, Weihong T, et al. Genome-wide association studies identify genetic loci for low von Willebrand factor levels. Eur J Hum Genet 2016;24(07):1035-1040

69 Antoni G, Oudot-Mellakh T, Dimitromanolakis A, et al. Combined analysis of three genome-wide association studies on vWF and FVIII plasma levels. BMC Med Genet 2011;12:102

70 van Schie MC, van Loon JE, de Maat MP, Leebeek FW. Genetic determinants of von Willebrand factor levels and activity in relation to the risk of cardiovascular disease: a review. J Thromb Haemost 2011;9(05):899-908

71 Gallinaro L, Cattini MG, Sztukowska M, et al. A shorter von Willebrand factor survival in O blood group subjects explains how $\mathrm{ABO}$ determinants influence plasma von Willebrand factor. Blood 2008;111(07):3540-3545

72 Millar CM, Brown SA. Oligosaccharide structures of von Willebrand factor and their potential role in von Willebrand disease. Blood Rev 2006;20(02):83-92

73 Franchini M, Capra F, Targher G, Montagnana M, Lippi G. Relationship between $\mathrm{ABO}$ blood group and von Willebrand factor levels: from biology to clinical implications. Thromb J 2007;5:14

74 Jenkins PV, O'Donnell JS. ABO blood group determines plasma von Willebrand factor levels: a biologic function after all? Transfusion 2006;46(10):1836-1844

75 Ozel AB, McGee B, Siemieniak D, et al. Genome-wide studies of von Willebrand factor propeptide identify loci contributing to variation in propeptide levels and von Willebrand factor clearance. J Thromb Haemost 2016;14(09):1888-1898

76 Desch KC, Ozel AB, Siemieniak D, et al. Linkage analysis identifies a locus for plasma von Willebrand factor undetected by genomewide association. Proc Natl Acad Sci U S A 2013;110(02): 588-593

77 Souto JC, Almasy L, Soria JM, et al. Genome-wide linkage analysis of von Willebrand factor plasma levels: results from the GAIT project. Thromb Haemost 2003;89(03):468-474

78 Keightley AM, Lam YM, Brady JN, Cameron CL, Lillicrap D. Variation at the von Willebrand factor (vWF) gene locus is associated with plasma vWF:Ag levels: identification of three novel single nucleotide polymorphisms in the vWF gene promoter. Blood 1999;93(12):4277-4283

79 van Schie MC, de Maat MP, Isaacs A, et al. Variation in the von Willebrand factor gene is associated with von Willebrand factor levels and with the risk for cardiovascular disease. Blood 2011; 117(04):1393-1399

80 van Loon JE, Kavousi M, Leebeek FW, et al. von Willebrand factor plasma levels, genetic variations and coronary heart disease in an older population. J Thromb Haemost 2012;10(07):1262-1269

81 Campos M, Sun W, Yu F, et al. Genetic determinants of plasma von Willebrand factor antigen levels: a target gene SNP and haplotype analysis of ARIC cohort. Blood 2011;117(19): $5224-5230$

82 Suadicani P, Hein HO, Gyntelberg F. Airborne occupational exposure, $A B O$ phenotype and risk of ischaemic heart disease in the Copenhagen Male Study. J Cardiovasc Risk 2002;9(04): 191-198

83 Marenberg ME, Risch N, Berkman LF, Floderus B, de Faire U. Genetic susceptibility to death from coronary heart disease in a study of twins. N Engl J Med 1994;330(15):1041-1046

84 Williams FM, Carter AM, Hysi PG, et al; EuroCLOT Investigators; Wellcome Trust Case Control Consortium 2; MOnica Risk, Genetics, Archiving and Monograph; MetaStroke; International Stroke Genetics Consortium. Ischemic stroke is associated with the ABO locus: the EuroCLOT study. Ann Neurol 2013;73(01):16-31

$85 \mathrm{Ay} \mathrm{H}$, Gungor L, Arsava EM, et al. A score to predict early risk of recurrence after ischemic stroke. Neurology 2010;74(02): 128-135

86 Arsava EM, Kim GM, Oliveira-Filho J, et al. Prediction of early recurrence after acute ischemic stroke. JAMA Neurol 2016;73 (04):396-401 
87 Sonneveld MA, van Dijk AC, van den Herik EG, et al. Relationship of Von Willebrand Factor with carotid artery and aortic arch calcification in ischemic stroke patients. Atherosclerosis 2013; 230(02):210-215

88 Ohira T, Shahar E, Chambless LE, Rosamond WD, Mosley TH Jr, Folsom AR. Risk factors for ischemic stroke subtypes: the Atherosclerosis Risk in Communities study. Stroke 2006;37(10): 2493-2498

89 Penz SM, Reininger AJ, Toth O, Deckmyn H, Brandl R, Siess W. Glycoprotein Ibalpha inhibition and ADP receptor antagonists, but not aspirin, reduce platelet thrombus formation in flowing blood exposed to atherosclerotic plaques. Thromb Haemost 2007;97(03):435-443

90 Hobl EL, Stimpfl T, Ebner J, et al. Morphine decreases clopidogrel concentrations and effects: a randomized, double-blind, placebo-controlled trial. J Am Coll Cardiol 2014;63(07):630-635

91 Spiel AO, Derhaschnig U, Schwameis M, Bartko J, Siller-Matula JM, Jilma B. Effects of prasugrel on platelet inhibition during systemic endotoxaemia: a randomized controlled trial. Clin Sci (Lond) 2012;123(10):591-600

92 Derhaschnig U, Pachinger C, Jilma B. Variable inhibition of highshear-induced platelet plug formation by eptifibatide and tirofiban under conditions of platelet activation and high von Willebrand release: a randomized, placebo-controlled, clinical trial. Am Heart J 2004;147(04):E17

93 Tobin WO, Kinsella JA, Kavanagh GF, et al. Longitudinal assessment of von Willebrand factor antigen and von Willebrand factor propeptide in response to alteration of antiplatelet therapy after TIA or ischaemic stroke. J Neurol 2014;261(07): 1405-1412

94 Nilsson TK, Spence JD, Nilsson PM, Eliasson M, Jansson JH, Boman K. Quantitative measurement of carotid atherosclerosis in relation to levels of von Willebrand factor and fibrinolytic variables in plasma-a 2-year follow-up study. J Cardiovasc Risk 2002;9 (04):215-221

95 National Institute of Neurological Disorders and Stroke rt-PA Stroke Study Group. Tissue plasminogen activator for acute ischemic stroke. N Engl J Med 1995;333(24):1581-1587

96 Hacke W, Kaste M, Bluhmki E, et al; ECASS Investigators. Thrombolysis with alteplase 3 to 4.5 hours after acute ischemic stroke. N Engl J Med 2008;359(13):1317-1329

97 Wardlaw JM, Murray V, Berge E, et al. Recombinant tissue plasminogen activator for acute ischaemic stroke: an updated systematic review and meta-analysis. Lancet 2012;379 (9834):2364-2372

98 Powers WJ, Derdeyn CP, Biller J, et al; American Heart Association Stroke Council. 2015 American Heart Association/American Stroke Association Focused Update of the 2013 Guidelines for the early management of patients with acute ischemic stroke regarding endovascular treatment: a guideline for healthcare professionals from the American Heart Association/American Stroke Association. Stroke 2015;46(10):3020-3035

99 Kleindorfer D, Lindsell CJ, Brass L, Koroshetz W, Broderick JP. National US estimates of recombinant tissue plasminogen activator use: ICD-9 codes substantially underestimate. Stroke 2008; 39(03):924-928

100 Adeoye O, Hornung R, Khatri P, Kleindorfer D. Recombinant tissue-type plasminogen activator use for ischemic stroke in the United States: a doubling of treatment rates over the course of 5 years. Stroke 2011;42(07):1952-1955

101 Wang Y, Liao X, Zhao X, et al; China National Stroke Registry Investigators. Using recombinant tissue plasminogen activator to treat acute ischemic stroke in China: analysis of the results from the Chinese National Stroke Registry (CNSR). Stroke 2011; 42(06):1658-1664

102 Barber PA, Zhang J, Demchuk AM, Hill MD, Buchan AM. Why are stroke patients excluded from TPA therapy? An analysis of patient eligibility. Neurology 2001;56(08):1015-1020
103 Cocho D, Belvís R, Martí-Fàbregas J, et al. Reasons for exclusion from thrombolytic therapy following acute ischemic stroke. Neurology 2005;64(04):719-720

104 O'Connor RE, McGraw P, Edelsohn L. Thrombolytic therapy for acute ischemic stroke: why the majority of patients remain ineligible for treatment. Ann Emerg Med 1999;33(01):9-14

105 Nogueira RG, Jadhav AP, Haussen DC, et al; DAWN Trial Investigators. Thrombectomy 6 to 24 hours after stroke with a mismatch between deficit and infarct. N Engl J Med 2018;378(01): $11-21$

106 Vivien D. Can the benefits of rtPA treatment for stroke be improved? Rev Neurol (Paris) 2017;173(09):566-571

107 Whiteley WN, Slot KB, Fernandes P, Sandercock P, Wardlaw J. Risk factors for intracranial hemorrhage in acute ischemic stroke patients treated with recombinant tissue plasminogen activator: a systematic review and meta-analysis of 55 studies. Stroke 2012;43(11):2904-2909

108 Montagne A, Hébert M, Jullienne A, et al. Memantine improves safety of thrombolysis for stroke. Stroke 2012;43(10): 2774-2781

109 Yeo LL, Paliwal P, Teoh HL, et al. Timing of recanalization after intravenous thrombolysis and functional outcomes after acute ischemic stroke. JAMA Neurol 2013;70(03):353-358

110 Molina CA, Montaner J, Arenillas JF, Ribo M, Rubiera M, AlvarezSabín J. Differential pattern of tissue plasminogen activatorinduced proximal middle cerebral artery recanalization among stroke subtypes. Stroke 2004;35(02):486-490

111 Goyal M, Menon BK, van Zwam WH, et al; HERMES collaborators. Endovascular thrombectomy after large-vessel ischaemic stroke: a meta-analysis of individual patient data from five randomised trials. Lancet 2016;387(10029):1723-1731

112 Singh B, Parsaik AK, Prokop LJ, Mittal MK. Endovascular therapy for acute ischemic stroke: a systematic review and meta-analysis. Mayo Clin Proc 2013;88(10):1056-1065

113 Sheth KN, Smith EE, Grau-Sepulveda MV, Kleindorfer D, Fonarow GC, Schwamm LH. Drip and ship thrombolytic therapy for acute ischemic stroke: use, temporal trends, and outcomes. Stroke 2015;46(03):732-739

114 Zhao W, Che R, Shang S, et al. Low-dose tirofiban improves functional outcome in acute ischemic stroke patients treated with endovascular thrombectomy. Stroke 2017;48(12): 3289-3294

115 O'Donnell MJ, Chin SL, Rangarajan S, et al; INTERSTROKE investigators. Global and regional effects of potentially modifiable risk factors associated with acute stroke in 32 countries (INTERSTROKE): a case-control study. Lancet 2016;388(10046):761-775

116 Kernan WN, Ovbiagele B, Black HR, et al; American Heart Association Stroke Council, Council on Cardiovascular and Stroke Nursing, Council on Clinical Cardiology, and Council on Peripheral Vascular Disease. Guidelines for the prevention of stroke in patients with stroke and transient ischemic attack: a guideline for healthcare professionals from the American Heart Association/American Stroke Association. Stroke 2014;45(07):2160-2236

117 Kamal AK, Naqvi I, Husain MR, Khealani BA. Cilostazol versus aspirin for secondary prevention of vascular events after stroke of arterial origin. Cochrane Database Syst Rev 2011;(01):CD008076

118 Li X, Zhou G, Zhou X, Zhou S. The efficacy and safety of aspirin plus dipyridamole versus aspirin in secondary prevention following TIA or stroke: a meta-analysis of randomized controlled trials. J Neurol Sci 2013;332(1-2):92-96

119 Committee CS; CAPRIE Steering Committee. A randomised, blinded, trial of clopidogrel versus aspirin in patients at risk of ischaemic events (CAPRIE). Lancet 1996;348(9038):1329-1339

120 Aldandashi S, Noor R, Wang CX, Uddin G, Shuaib A. Combination treatment with dipyridamole, aspirin, and tPA in an embolic model of stroke in rats. Exp Neurol 2007;205(02):563-568

121 Lee JH, Park SY, Lee WS, Hong KW. Lack of antiapoptotic effects of antiplatelet drug, aspirin and clopidogrel, and antioxidant, MCI- 
186, against focal ischemic brain damage in rats. Neurol Res 2005;27(05):483-492

122 Sacco RL, Diener HC, Yusuf S, et al; PRoFESS Study Group. Aspirin and extended-release dipyridamole versus clopidogrel for recurrent stroke. N Engl J Med 2008;359(12):1238-1251

123 Rothwell PM, Algra A, Chen Z, Diener HC, Norrving B, Mehta Z. Effects of aspirin on risk and severity of early recurrent stroke after transient ischaemic attack and ischaemic stroke: time-course analysis of randomised trials. Lancet 2016;388(10042):365-375

124 Bath PM, Cotton D, Martin RH, et al; PRoFESS Study Group. Effect of combined aspirin and extended-release dipyridamole versus clopidogrel on functional outcome and recurrence in acute, mild ischemic stroke: PRoFESS subgroup analysis. Stroke 2010;41 (04):732-738

125 Zhang Q, Wang C, Zheng M, et al. Aspirin plus clopidogrel as secondary prevention after stroke or transient ischemic attack: a systematic review and meta-analysis. Cerebrovasc Dis 2015;39 (01):13-22

126 Diener HC, Bogousslavsky J, Brass LM, et al; MATCH investigators. Aspirin and clopidogrel compared with clopidogrel alone after recent ischaemic stroke or transient ischaemic attack in highrisk patients (MATCH): randomised, double-blind, placebo-controlled trial. Lancet 2004;364(9431):331-337

127 Hilkens NA, Li L, Rothwell PM, Algra A, Greving JP. External validation of risk scores for major bleeding in a population-based cohort of transient ischemic attack and ischemic stroke patients. Stroke 2018;49(03):601-606

128 Moake JL, Turner NA, Stathopoulos NA, Nolasco L, Hellums JD. Shear-induced platelet aggregation can be mediated by vWF released from platelets, as well as by exogenous large or unusually large vWF multimers, requires adenosine diphosphate, and is resistant to aspirin. Blood 1988;71(05):1366-1374

129 Rosafio F, Lelli N, Mimmi S, et al. Platelet function testing in patients with acute ischemic stroke: an observational study. J Stroke Cerebrovasc Dis 2017;26(08):1864-1873

130 Kunicki TJ, Williams SA, Nugent DJ, et al. Lack of association between aspirin responsiveness and seven candidate gene haplotypes in patients with symptomatic vascular disease. Thromb Haemost 2009;101(01):123-133

131 Wang Y, Zhao X, Lin J, et al; CHANCE investigators. Association between CYP2C19 loss-of-function allele status and efficacy of clopidogrel for risk reduction among patients with minor stroke or transient ischemic attack. JAMA 2016;316(01):70-78

132 Pan Y, Chen W, Xu Y, et al. Genetic polymorphisms and clopidogrel efficacy for acute ischemic stroke or transient ischemic attack: a systematic review and meta-analysis. Circulation 2017; 135(01):21-33

133 Lin Y, Wang A, Li J, et al; CHANCE Investigators. Impact of glycemic control on efficacy of clopidogrel in transient ischemic attack or minor stroke patients with CYP2C19 genetic variants. Stroke 2017;48(04):998-1004

134 Li X, Ling L, Li C, Ma Q. Efficacy and safety of desmoteplase in acute ischemic stroke patients: a systematic review and metaanalysis. Medicine (Baltimore) 2017;96(18):e6667

135 Le Behot A, Gauberti M, Martinez De Lizarrondo S, et al. GpIb $\alpha$ VWF blockade restores vessel patency by dissolving platelet aggregates formed under very high shear rate in mice. Blood 2014;123(21):3354-3363

136 Momi S, Tantucci M, Van Roy M, Ulrichts H, Ricci G, Gresele P. Reperfusion of cerebral artery thrombosis by the GPIb-VWF blockade with the Nanobody ALX-0081 reduces brain infarct size in guinea pigs. Blood 2013;121(25):5088-5097

137 Denorme F, Langhauser F, Desender L, et al. ADAMTS13mediated thrombolysis of t-PA-resistant occlusions in ischemic stroke in mice. Blood 2016;127(19):2337-2345

138 Fan $\mathrm{M}, \mathrm{Xu} \mathrm{H}$, Wang L, et al. Tissue plasminogen activator neurotoxicity is neutralized by recombinant ADAMTS 13. Sci Rep 2016;6:25971
139 Gilbert JC, DeFeo-Fraulini T, Hutabarat RM, et al. First-in-human evaluation of anti von Willebrand factor therapeutic aptamer ARC1779 in healthy volunteers. Circulation 2007;116(23): 2678-2686

140 Knöbl P, Jilma B, Gilbert JC, Hutabarat RM, Wagner PG, JilmaStohlawetz P. Anti-von Willebrand factor aptamer ARC1779 for refractory thrombotic thrombocytopenic purpura. Transfusion 2009;49(10):2181-2185

141 Peyvandi F, Scully M, Kremer Hovinga JA, et al; TITAN Investigators. Caplacizumab for acquired thrombotic thrombocytopenic purpura. N Engl J Med 2016;374(06):511-522

142 Cataland SR, Peyvandi F, Mannucci PM, et al. Initial experience from a double-blind, placebo-controlled, clinical outcome study of ARC1779 in patients with thrombotic thrombocytopenic purpura. Am J Hematol 2012;87(04):430-432

143 Jilma B, Paulinska P, Jilma-Stohlawetz P, Gilbert JC, Hutabarat R, Knöbl P. A randomised pilot trial of the anti-von Willebrand factor aptamer ARC1779 in patients with type $2 \mathrm{~b}$ von Willebrand disease. Thromb Haemost 2010;104(03):563-570

144 Eikelboom JW, Connolly SJ, Bosch J, et al; COMPASS Investigators. Rivaroxaban with or without aspirin in stable cardiovascular disease. N Engl J Med 2017;377(14):1319-1330

145 Johnston SC, Amarenco P, Albers GW, et al; SOCRATES Steering Committee and Investigators. Ticagrelor versus aspirin in acute stroke or transient ischemic attack. N Engl J Med 2016;375(01): 35-43

146 Amarenco P, Albers GW, Denison H, et al; SOCRATES Steering Committee and Investigators. Efficacy and safety of ticagrelor versus aspirin in acute stroke or transient ischaemic attack of atherosclerotic origin: a subgroup analysis of SOCRATES, a randomised, double-blind, controlled trial. Lancet Neurol 2017;16(04):301-310

147 Toyoda K PRASTRO-1 Study - A Comparison of Prasugrel and Clopidogrel (Standard of Care); 2017 [Abstract]. Available at: http://eso-stroke.org/kategorie-1/esoc-2017-highlights-day-3/. Accessed November 15, 2017

148 Bonaca MP, Scirica BM, Braunwald E, et al. New ischemic stroke and outcomes with vorapaxar versus placebo: results from the TRA $2{ }^{\circ}$ P-TIMI 50 trial. J Am Coll Cardiol 2014;64(22):2318-2326

149 Wang Y, Wang Y, Zhao X, et al; CHANCE Investigators. Clopidogrel with aspirin in acute minor stroke or transient ischemic attack. N Engl J Med 2013;369(01):11-19

150 Li Z, Wang Y, Zhao X, et al; CHANCE Investigators. Treatment effect of clopidogrel plus aspirin within 12 hours of acute minor stroke or transient ischemic attack. J Am Heart Assoc 2016;5 (03):e003038

151 De Meyer SF, Schwarz T, Deckmyn H, et al. Binding of von Willebrand factor to collagen and glycoprotein Ibalpha, but not to glycoprotein IIb/IIIa, contributes to ischemic stroke in mice-brief report. Arterioscler Thromb Vasc Biol 2010;30(10): 1949-1951

152 Van Bockstaele F, Holz JB, Revets H. The development of nanobodies for therapeutic applications. Curr Opin Investig Drugs 2009;10(11):1212-1224

153 Ablynx announces positive topline results from the phase III hercules study of caplacizumab for the treatment of acquired TTP. 2017

154 Keefe AD, Pai S, Ellington A. Aptamers as therapeutics. Nat Rev Drug Discov 2010;9(07):537-550

155 Markus HS, McCollum C, Imray C, Goulder MA, Gilbert J, King A. The von Willebrand inhibitor ARC1779 reduces cerebral embolization after carotid endarterectomy: a randomized trial. Stroke 2011;42(08):2149-2153

156 Jang IK, Gold HK, Ziskind AA, et al. Differential sensitivity of erythrocyte-rich and platelet-rich arterial thrombi to lysis with recombinant tissue-type plasminogen activator. A possible explanation for resistance to coronary thrombolysis. Circulation 1989;79(04):920-928 
157 Tomkins AJ, Schleicher N, Murtha L, et al. Platelet rich clots are resistant to lysis by thrombolytic therapy in a rat model of embolic stroke. Exp Transl Stroke Med 2015;7:2

158 Bustamante AL, Boada C, Penalba A, et al. ADAMTS13 Activity Predicts Response to Thrombolysis in the Acute Stroke Setting. Stroke Suppl 2015

159 Borggrefe J, Kottlors J, Mirza M, et al. Differentiation of clot composition using conventional and dual-energy computed tomography. Clin Neuroradiol 2017

160 Mazighi M, Tanasescu R, Ducrocq X, et al. Prospective study of symptomatic atherothrombotic intracranial stenoses: the GESICA study. Neurology 2006;66(08):1187-1191

161 Chimowitz MI, Lynn MJ, Derdeyn CP, et al; SAMMPRIS Trial Investigators. Stenting versus aggressive medical therapy for intracranial arterial stenosis. N Engl J Med 2011;365(11): 993-1003

162 Kasner SE, Chimowitz MI, Lynn MJ, et al; Warfarin Aspirin Symptomatic Intracranial Disease Trial Investigators. Predictors of ischemic stroke in the territory of a symptomatic intracranial arterial stenosis. Circulation 2006;113(04):555-563

163 Zaidat OO, Fitzsimmons BF, Woodward BK, et al; VISSIT Trial Investigators. Effect of a balloon-expandable intracranial stent vs medical therapy on risk of stroke in patients with symptomatic intracranial stenosis: the VISSIT randomized clinical trial. JAMA 2015;313(12):1240-1248

164 Kim D, Lee SH, Joon Kim B, et al; for Korean Stroke Registry investigators. Secondary prevention by stroke subtype: a nationwide follow-up study in 46108 patients after acute ischaemic stroke. Eur Heart J 2013;34(35):2760-2767

165 Sonneveld MA, Kavousi M, Ikram MA, et al. Low ADAMTS-13 activity and the risk of coronary heart disease - a prospective cohort study: the Rotterdam Study. J Thromb Haemost 2016;14 (11):2114-2120

166 Kageyama S, Yamamoto H, Yoshimoto R. Anti-human von willebrand factor monoclonal antibody AJvW-2 prevents thrombus deposition and neointima formation after balloon injury in guinea pigs. Arterioscler Thromb Vasc Biol 2000;20(10): 2303-2308

167 Zahger D, Fishbein MC, Garfinkel LI, et al. VCL, an antagonist of the platelet GP1b receptor, markedly inhibits platelet adhesion and intimal thickening after balloon injury in the rat. Circulation 1995;92(05):1269-1273

168 Yamashita A, Asada Y, Sugimura H, et al. Contribution of von Willebrand factor to thrombus formation on neointima of rabbit stenotic iliac artery under high blood-flow velocity. Arterioscler Thromb Vasc Biol 2003;23(06):1105-1110

169 Gandhi C, Khan MM, Lentz SR, Chauhan AK. ADAMTS13 reduces vascular inflammation and the development of early atherosclerosis in mice. Blood 2012;119(10):2385-2391

170 Jin SY, Tohyama J, Bauer RC, Cao NN, Rader DJ, Zheng XL. Genetic ablation of Adamts13 gene dramatically accelerates the formation of early atherosclerosis in a murine model. Arterioscler Thromb Vasc Biol 2012;32(08):1817-1823

171 LaMuraglia GM, Stoner MC, Brewster DC, et al. Determinants of carotid endarterectomy anatomic durability: effects of serum lipids and lipid-lowering drugs. J Vasc Surg 2005;41(05): 762-768

172 Engelter S, Lyrer P. Antiplatelet therapy for preventing stroke and other vascular events after carotid endarterectomy. Cochrane Database Syst Rev 2003;(03):CD001458

173 Matas M, Domínguez González JM, Montull E. Antiplatelet therapy in endovascular surgery: the RENDOVASC study. Ann Vasc Surg 2013;27(02):168-177

174 Roubin GS, Yadav S, Iyer SS, Vitek J. Carotid stent-supported angioplasty: a neurovascular intervention to prevent stroke. Am J Cardiol 1996;78(3A):8-12
175 Diethrich EB, Ndiaye M, Reid DB. Stenting in the carotid artery: initial experience in 110 patients. J Endovasc Surg 1996;3(01): 42-62

176 Bergeron P, Roux M, Khanoyan P, Douillez V, Bras J, Gay J. Longterm results of carotid stenting are competitive with surgery. J Vasc Surg 2005;41(02):213-221

177 Kefer JM, Galanti LM, Desmet S, Deneys V, Hanet CE. Time course of release of inflammatory markers after coronary stenting: comparison between bare metal stent and sirolimus-eluting stent. Coron Artery Dis 2005;16(08):505-509

178 Blann A, Midgley H, Burrows G, et al. Free radicals, antioxidants, and endothelial cell damage after percutaneous transluminal coronary angioplasty. Coron Artery Dis 1993;4(10):905-910

179 Robless PA, Tegos TJ, Okonko D, et al. Platelet activation during carotid endarterectomy and the antiplatelet effect of Dextran 40 . Platelets 2002;13(04):231-239

180 Yang H, Xu JX, Kong XZ, et al. Relations between plasma von Willebrand factor or endothelin-1 and restenosis following carotid artery stenting. Med Princ Pract 2012;21(06):538-542

181 Davis JA, Brown AT, Alshafie T, et al. Saratin (an inhibitor of plateletcollagen interaction) decreases platelet aggregation and homocysteine-mediated postcarotid endarterectomy intimal hyperplasia in a dose-dependent manner. Am J Surg 2004;188(06):778-785

182 Wang W, Jiang B, Sun H, et al; NESS-China Investigators. Prevalence, incidence, and mortality of stroke in China: results from a nationwide population-based survey of 480687 adults. Circulation 2017;135(08):759-771

183 Niu JW, Gao S, Cui LY, et al. Intracranial atherosclerosis in Chinese young adult stroke patients. J Stroke Cerebrovasc Dis 2014;23 (06):1519-1523

184 Smith A, Patterson C, Yarnell J, Rumley A, Ben-Shlomo Y, Lowe G. Which hemostatic markers add to the predictive value of conventional risk factors for coronary heart disease and ischemic stroke? The Caerphilly Study. Circulation 2005;112(20):3080-3087

185 Wieberdink RG, van Schie MC, Koudstaal PJ, et al. High von Willebrand factor levels increase the risk of stroke: the Rotterdam study. Stroke 2010;41(10):2151-2156

186 Wannamethee SG, Whincup PH, Lennon L, Rumley A, Lowe GD. Fibrin D-dimer, tissue-type plasminogen activator, von Willebrand factor, and risk of incident stroke in older men. Stroke 2012;43(05):1206-1211

187 Jilma-Stohlawetz P, Knöbl P, Gilbert JC, Jilma B. The anti-von Willebrand factor aptamer ARC1779 increases von Willebrand factor levels and platelet counts in patients with type $2 \mathrm{~B}$ von Willebrand disease. Thromb Haemost 2012;108(02):284-290

188 Jilma-Stohlawetz P, Gorczyca ME, Jilma B, Siller-Matula J, Gilbert JC, Knöbl P. Inhibition of von Willebrand factor by ARC1779 in patients with acute thrombotic thrombocytopenic purpura. Thromb Haemost 2011;105(03):545-552

189 Jilma-Stohlawetz P, Gilbert JC, Gorczyca ME, Knöbl P, Jilma B. A dose ranging phase I/II trial of the von Willebrand factor inhibiting aptamer ARC1779 in patients with congenital thrombotic thrombocytopenic purpura. Thromb Haemost 2011;106 (03):539-547

190 Machin SJ, Clarke C, Ikemura O, et al. A humanized monoclonal antibody against vWF A1 domain inhibits vWF:RiCof activity and platelet adhesion in human volunteers. J Thromb Haemost 2003; 1:Abstract OC328

191 Scully M, Knöbl P, Kentouche K, et al. Recombinant ADAMTS-13: first-in-human pharmacokinetics and safety in congenital thrombotic thrombocytopenic purpura. Blood 2017;130(19): 2055-2063

192 Hou Y, Reheman A, Li BX, et al. Abstract 499: Development of a Novel Antithrombotic Therapy Targeting Platelet GPIbo: Assessment of Anfibatide In Vitro and in Phase I Clinical Trial. Arterioscler Thromb Vasc Biol 2014;34(Suppl 1):A499 